\title{
Duke-Elder Lecture
}

\section{Retinal Arteritis, Retinal Vasculitis and Autoimmune Retinal Vasculitis}

\author{
M. D. SANDERS \\ London
}

I would like to thank the President and Council for honouring me with the task of delivering the 4th Duke-Elder Lecture, and enabling me to pay tribute to one of the most distinguished British Ophthalmologists of this century.

Born near Dundee in 1898, Sir Stewart Duke-Elder graduated from St Andrew's University with a BSc and special distinction in physiology. After medical training in Dundee and Edinburgh he graduated, and like many of his compatriots took the high road south to London, where he was fortunate in gaining the close friendship of one of London's most illustrious scientific ophthalmologists, Sir Herbert Parsons. His career progressed after appointments at Moorfields Eye Hospital and St George's Hospital, to attain the highest accolades available in his own land, and his international reputation similarly grew as he received honours abroad.

His phenomenal ability to condense, concentrate and clarify, enabled him to write the greatest textbook of ophthalmology ever produced. His broad scientific scholarship enabled him to initiate and direct the Institute of Ophthalmology in London, which he expanded to become an institute of world renown.

Sir Stewart had some influence on the nature of this lecture by two actions. In 1954 he supported the establishment of a Medical Eye Unit at the Royal Eye Hospital under the directorship of Professor Arnold Sorsby. This Unit was subsequently transferred to St Thomas' with the Royal Eye Hospital in 1973. Staffed by physicians, neurologists and ophthalmologists, the Unit has provided a base for itensive in-patient investigation of complicated medical and neuro-ophthalmic problems. Secondly, he was instrumental in this author obtaining the Alexander Piggott Warner Memorial Fellowship to study at the University of California, San Francisco, in 1967-1968 under Professor W. F. Hoyt.

On joining the staff of the Medical Eye Unit at St Thomas' Hospital, it became clear to me that 'Retinal Vasculitis' was a major cause of visual morbidity and occurred particularly in young people. In America, 10 per cent of patients with severe visual handicap were noted to have inflammatory eye disease. ${ }^{1}$ In many cases retinal changes occurred in the context of a systemic disease and the ocular changes provided specific diagnostic clues to the systemic disease. Retinal veins were predominantly involved, although in some conditions the arteries appeared to bear the brunt of the disease. Complex immunological investigations were performed in addition to full ophthalmic examination so that the natural history of the disease has been observed over a period of 10 years. This paper will therefore present clinical and immunological information on 150 cases of retinal vasculitis seen at St Thomas' between 1975

From: National Hospital for Nervous Diseases and St Thomas' Hospital, London.

Correspondence to: Mr. M. D. Sanders, FRCP, FRCS, Consultant Ophthalmologist, National Hospital for Nervous Diseases, Queen Square, London WC1.

Presented at the Annual Congress of the Ophthalmological Society of the United Kingdom, April 1987. 
and 1985 which have been subdivided into those with an associated systemic inflammatory disease and those with isolated 'Autoimmune Retinal Vasculitis'. All cases were deemed to have immune mediated vasculitis and in all cases inflammatory causes were actively excluded. The role of auto-immunity has been established clinically and by the development of an experimental animal model which has enabled us to make immunological, neurophysiological, pathological and therapeutic observation.

\section{Historical Aspects}

The concept of inflammation of the veins was first established by another outstanding Scotsman in 1784, when John Hunter first published a paper on 'Observations on the Inflammation of the Internal Coats of the Veins'. ${ }^{2}$ Inflammation of the retinal vessels was noted over 100 years later in pathological specimens by Parsons. ${ }^{3}$ In 1890 a Birmingham ophthalmologist, Henry Eales ${ }^{4}$ described 5 cases of young men suffering from constipation, epistaxis and associated retinal haemorrhages. Though a high arterial tension was described, in no patient was the sphygmomanometer used. A tuberculous origin was postulated by Axenfeld and Stock ${ }^{5}$ and it is probable that this was the cause of the condition Eales described though he obtained no aetiological information in any of his cases. The association of inflammatory changes in the retinal vessels with uveitis and systemic diseases became well-recognised, ${ }^{6,7,8}$ but a strict nosological entity was not established. A form of central 'Retinal Vasculitis' was described by Lyle and Wybar ${ }^{9}$ but evidence for an inflammatory basis has never been established and Hart and others ${ }^{10}$ considered this an haematological disorder, though extensive investigations have failed to elicit the initiating cause.

\section{Terminological Aspects}

Confusion has persisted over the terminology of inflammatory conditions of the eye. Many terms evolved on anatomical grounds without sufficient clinical, experimental or pathological information being available. Iritis was recognised by the ancients as an inflammation of the anterior portion of the eye and later related to both arthritic and scrofular conditions. ${ }^{11}$ The advent of the ophthalmoscope allowed advances in the diagnosis of retinal and choroidal conditions and choroiditis became recognised. ${ }^{12}$ Combined inflammation in the iris and choroid was termed uveitis, which relates to the uvea or grape-like coat of the eye, due to its similarity to a black grape. Improved examination of the eye by the slit lamp and indirect ophthalmoscopy resulted in the recognition of peripheral uveitis.

Inflammation of the ciliary body has been termed peripheral uveitis, ${ }^{13}$ pars planitis ${ }^{14}$ and more recently intermediate uveitis.

Some revision of this classifiation now seems appropriate with the realisation that the retina contains many powerful antigens, and may be more immunologically active than the uvea. The recent availability of monoclonal antibodies and the detection of retinal antibodies should allow a more precise categorisation of ocular inflammatory disease. It does appear that retinal vasculitis emerges as a distinct clinical entity though the primary immunological event may be directed against constituents of the photoreceptor cells. The retina is presented to the immune system by the retinal vessels and thus the predominant clinical and inflammatory events occur in relation to these vessels. Many of the conditions producing retinal disease have been previously termed uveitis, though the author agrees with Maumenee ${ }^{15}$ who stated that inflammation of the uvea as a primary event is rare and the term uveitis as generally applied is inappropriate.

\section{Vasculitis-The Clinical Spectrum}

Vasculitis is a clinico-pathological process characterised by inflammation and necrosis of blood vessels. In some diseases vasculitis may be a major feature, whereas in other diseases it occurs as a secondary phenomenon. Vessels of any size, and situated in any organ may be involved. An association either direct or indirect can be established with immunopathogenic mechanisms and immune complexes mediation is being increasingly recognised as the underlying mechanism. ${ }^{16}$

The prevailing theory relates to primary or secondary deposition of immune complexes in 
blood vessel walls, and elegant animal models support these hypotheses. ${ }^{17}$

Necrotising vasculitis was first described by Kussmaul and Maier in $1866^{18}$ in a 27 year old man with classic periarteritis nodosa. Systemic vasculitis is recognised as an important feature of several of the connective tissue or collagen vascular diseases such as rheumatoid arthritis and detectable immune system abnormalities such as hypergammaglobulinaemia, rheumatoid factor, cryoglobulinaemia, circulating immune complexes and hypocomplementaemia also testify to an immunological aberration.

A relationship with viral induced disease such as hepatitis B, antigen-associated necrotising vasculitis, or to drug induced hypersensitivity reactions raises the question of multiple triggering mechanisms.

$\begin{array}{ll}\text { Polyarteritis } & \text { Classic } \\ \text { nodosa } & \begin{array}{l}\text { Allergic granulomatosis } \\ \text { Systemic necrotising }\end{array} \\ \text { Hypersensitivity } & \text { Churg Strauss Syndrome } \\ \text { Vasculitis } & \begin{array}{l}\text { Henoch Schonlein } \\ \text { purpura }\end{array} \\ & \text { Essential mixed } \\ & \text { cryoglobulinaemia } \\ & \text { Vasculitis with } \\ & \text { malignancies }\end{array}$

Wegeners

granulomatosis

$\begin{array}{ll}\text { Giant cell } & \text { Giant cell arteritis } \\ \text { arteritis } & \text { Takayasus arteritis }\end{array}$

Thrombo angiitis

obliterans

Classifications have also been attempted on the size of the vessel involved and this has many practical advantages. ${ }^{19}$ In certain parts of the body predisposing factors may influence the pattern of vasculitis as exemplified in the skin. In immune complex disease, lesions can be produced in the skin by pressure, suction or trauma, such as injuring the skin with a pin prick..$^{20}$ Thus in dermatology a wide spectrum of skin lesions may represent vasculitis, which can be evaluated histologically and subjected to immunopathologic study. Furthermore, certain skin diseases. (e.g. leucocytoclastic angiitis) may represent a mul- titude of different causes.

Similarly when the kidney is involved there is the potential for histological examination and evidence has accrued that DNA related antibodies have a predeliction for deposition in the kidney.

Thus there is a wide spectrum of vasculitis in the body, and the ophthalmologist must be aware of some of these conditions in order to provide diagnostic advice. However, the retinal vessels are unique in providing a substrate in which a microcirculation may be studied with great precision. The ophthalmologist therefore has a major role in clarifying the nosological and diagnostic debate in patients with vasculitis.

The aim of this lecture is to concentrate the attentions of ophthalmologists on the retina and the retinal vessels as being ' $a$ priori' source of immunopathogenic activity and to escape from the conventional view that inflammatory ocular disease is labelled under the all encompassing blanket term 'uveitis'.

Retinal vasculitis should be considered when major inflammatory changes occur in relation to the retinal vessels, often with accompanying signs in the retina or the vitreous. The veins may demonstrate sheathing, which may be extensive or focal, and in addition there may be haemorrhages or infiltrates in the retina. Capillary involvement may be suspected when there is retinal swelling or cystoid maculopathy. Involvement of the arteries is suggested by sheathing or occlusion.

These clinical signs may be confirmed by fluorescein angiography, which demonstrates leakage of dye due to breakdown of normal integrity of the blood/retinal barrier. Histological examination corroborates these findings by demonstrating:

(1) Perivasculitis, with cuffing of the vessels by inflammatory cells. In addition, immunohistocytochemical stains may show immunoglobulins or components or complement deposited in vessel walls, suggesting the deposition of immune complexes.

(2) Fibrinoid thrombosis in arteries resulting from an immunopathological event but without the characteristic cellular response. 
Differential Diagnosis and the Diagnostic

\section{Dartboard}

The clinician presented with a patient with retinal vasculitis must realise that this is a sight-threatening disease and that a full and explicit history is essential. Particular emphasis must be placed on other systemic manifestations, on past medical conditions, on foreign travel, on drug exposure and sexual peculiarities. A useful method of discussing the differential diagnosis is with the aid of the diagnostic dartboard (Fig. 1), which provides a list of sub-groups of conditions which may simulate retinal vasculitis clinically, on fluorescein angiography and on histological examination. These include infections, malignant disease, ischaemic disease, and retinal degenerations (outer circle). ${ }^{21}$ As the circles pro-

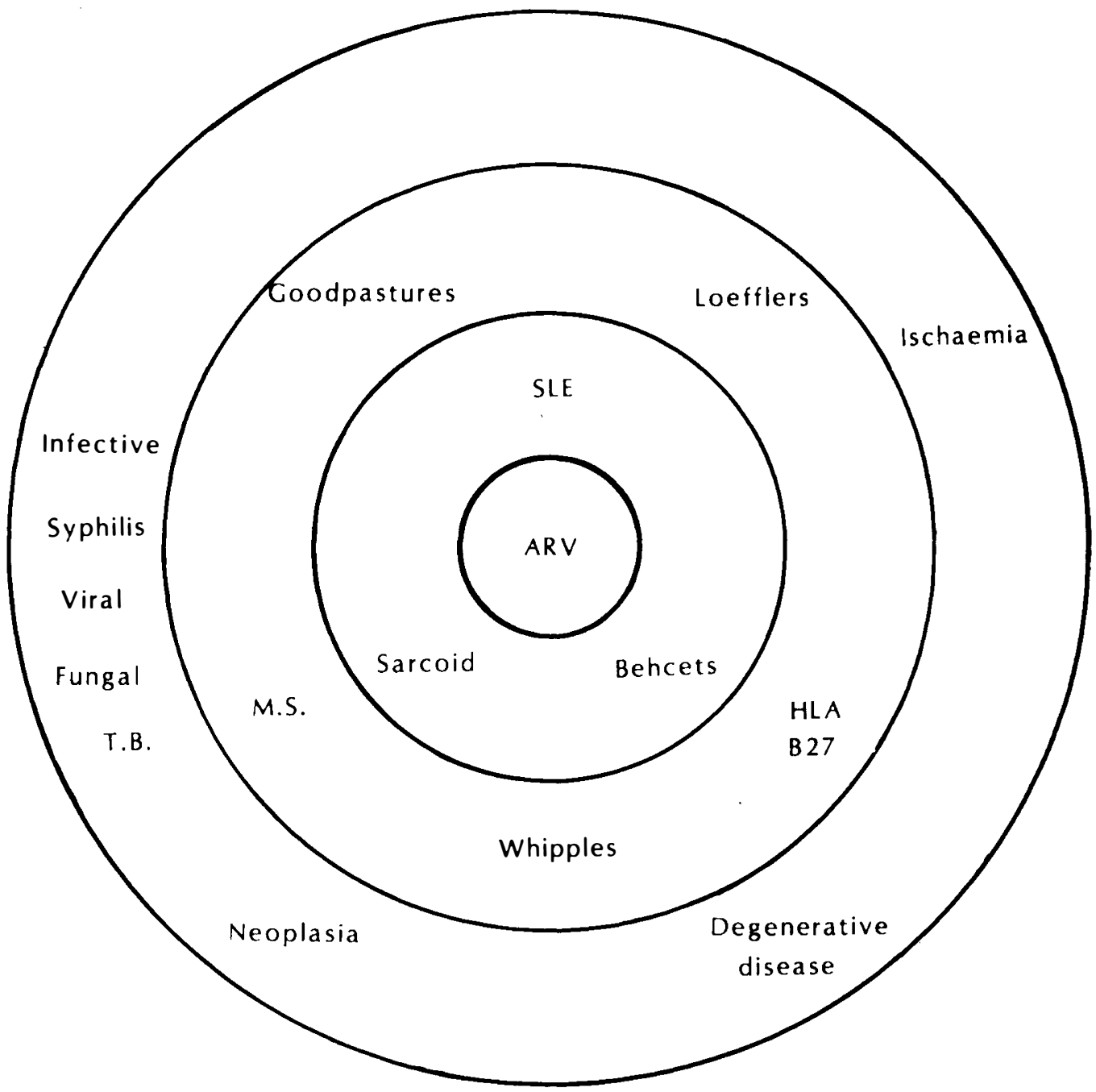

Fig. 1. Diagnostic Dartboard for Retinal Vasculitis

Outer Circle: Conditions that simulate autoimmune retinal vasculitis but which may be amenable to treatment. These include (a) Infections; (b) Neoplastic conditions; (c) Degenerative conditions; (d) Ischaemic disease.

Middle Circle: Rare causes of retinal vasculitis, PAN and Loefflers produce retinal arteritis.

Inner Circle: Common causes of retinal vasculitis with systemic disease.

Bull's Eye: Autoimmune retinal Vasculitis-an organ specific autoimmune disease. 
ceed towards the centre there is an increasing incidence of true vasculitis and this paper will discuss these conditions in that order.

\section{(a) Infectious Diseases}

A wide variety of infectious agents may involve the retina, and other clinical signs should be heeded and appropriate investigative tests should be contemplated in all patients. In particular, patients who show signs of deterioration after initial recovery on steroid treatment particularly should be investigated. A brief review of some of the infective causes which may present to the ophthalmologist will be considered.

\section{(1) Tuberculosis}

Retinal vasculitis may be the presenting sign of tuberculosis. This association may have been more common previously and established tuberculosis was found in a third of 31 patients with retinal periphlebitis. ${ }^{22}$ The aetiology of retinal vasculitis in the patients described by Eales ${ }^{4}$ has not been established but tuberculosis diseases may be suspected. Pathological examination has shown that granulomatous lesions may surround the retinal vessels. ${ }^{23}$ Six patients considered to have retinal vasculitis over the past 10 years were found to have tuberculosis and this may be the presenting feature of tuberculosis. ${ }^{24}$ The diagnosis should be particularly suspected in Asian patients, or those with a history of contact with open tuberculosis, and Mantoux tests, chest $\mathrm{X}$-rays and organism culture are obligatory.

\section{(2) Viral Infections}

Acute retinal necrosis presents as a peripheral confluent, necrotising retinitis, with retinal arteritis, papillitis and subsequent retinal detachment. First described in the Japanese literature ${ }^{25}$ as a unilateral condition, bilateral cases were subsequently reported. ${ }^{26}$ Herpes virus has since been isolated in a number of cases and though it may arise in normal adults, there is a particular predeliction for immunocompromised patients (Fig. 2a). Clinical and light microscopic findings suggest direct involvement of retinal arteries, and $T$ cells are thought to respond to HSV antigens and also occur on the endothelial cell membrane of retinal arterioles. The associated choroiditis may be a secondary response. ${ }^{27}$ Cytomegalovirus and other viruses may also be responsible, and with the advent of viral therapy diagnosis assumes an urgent role.

\section{(3) Syphilis}

Inflammatory disease due to syphilis is important to recognise because of the therapeutic possibilities. Clinically anterior uveitis, retinal vasculities and inflammatory papillitis may be seen and pathologically there is a perivascular infiltration with lymphocytes and plasma cells. ${ }^{28}$ Occlusive vascular diseases may be seen due to endothelial and glial cell proliferation. A full and explicit history is essential, clinical examination may support the diagnosis and supportive diagnostic tests (VDRL, TPHA and FTAs) will be confirmatory. The ocular signs usually occur as a manifestation of secondary syphilis though it has been reported in the tertiary stage.

\section{(4) Fungus Infections}

The immunocompromised patients, the drug abuser and patients on continuous intravenous therapy are vulnerable to fungus infections. Presenting as unilateral or bilateral uveitis, the response to steroids is not sustained and vitreous biopsy clarifies the diagnosis. Candida albicans is a frequent cause, and specific antifungal treatment is available.

\section{(b) Degenerative Retinal Disease}

Several studies have established the leakage of dye that occurs in relation to the retinal vessels in retinitis pigmentosa. Fluorescein leakage was noted in 26 per cent of 70 patients with retinitis pigmentosa by Newsome ${ }^{29}$ and leakage may occur at the disc, at the macula, or along the arcuate nerve fibre bundles. ${ }^{30}$ Leakage was seen in all genetic types of retinitis pigmentosa and in some cases retinal telangiectasia has been reported similar to Coats' disease. ${ }^{31}$ No clear explanation for the leakage has emerged, though the extensive degeneration of the retina may similarly involve vascular endothelial cells. Alternatively, retinal autoimmunity may play a role, ${ }^{32}$ as antiretinal antibodies have been detected. The importance of the astrocyte in 


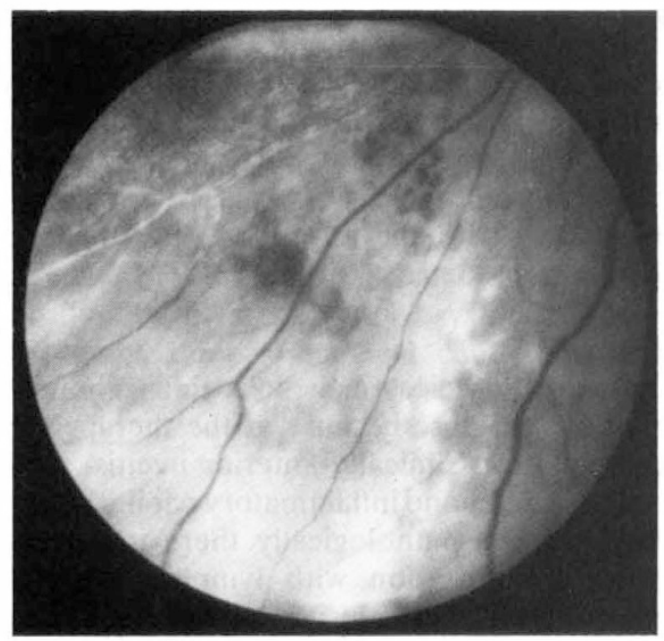

(a)

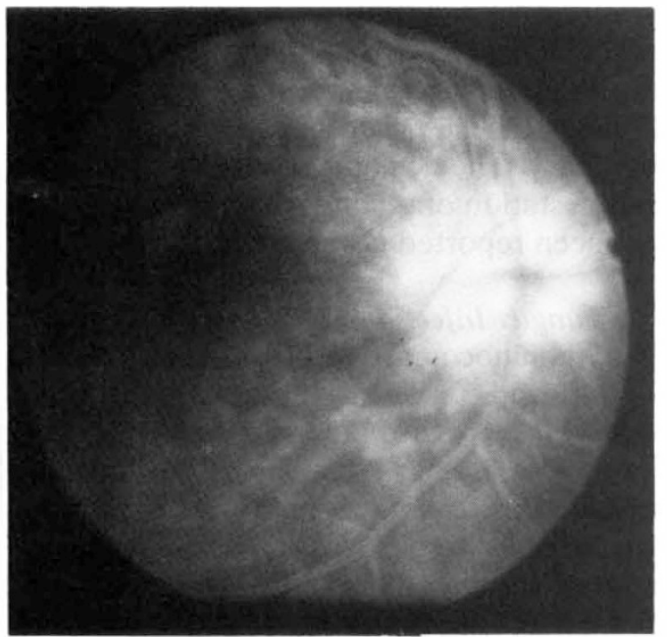

(c) left

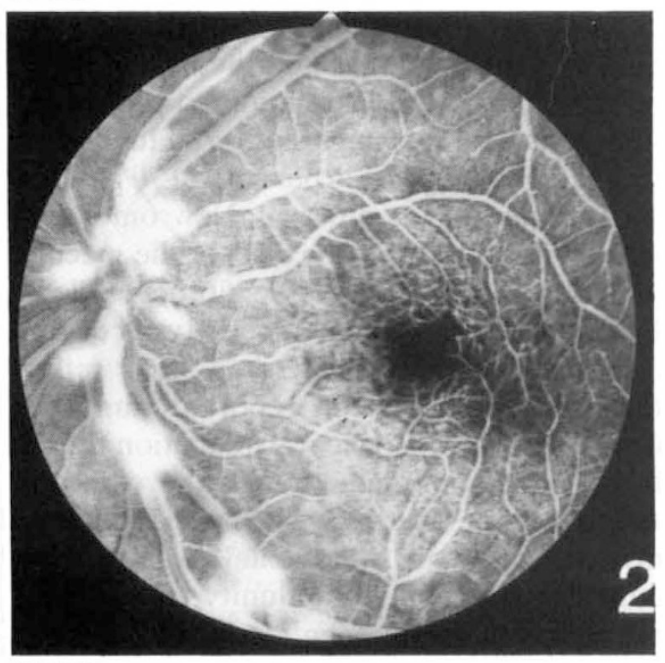

(d) left

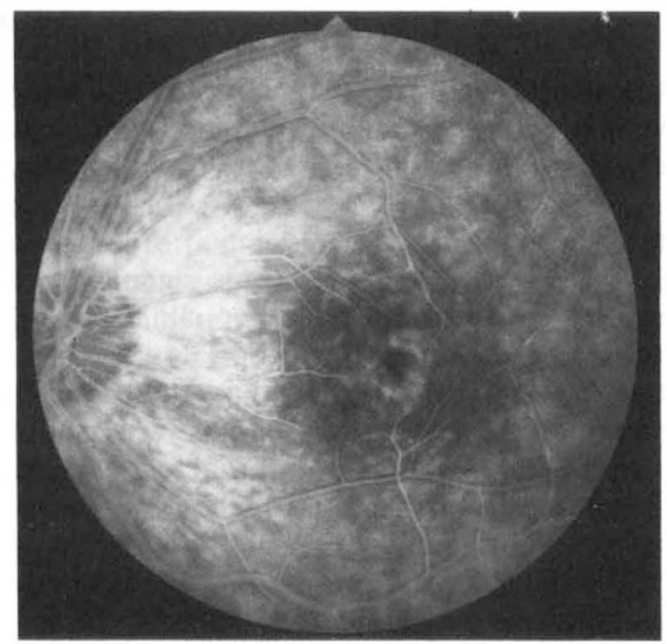

(b)
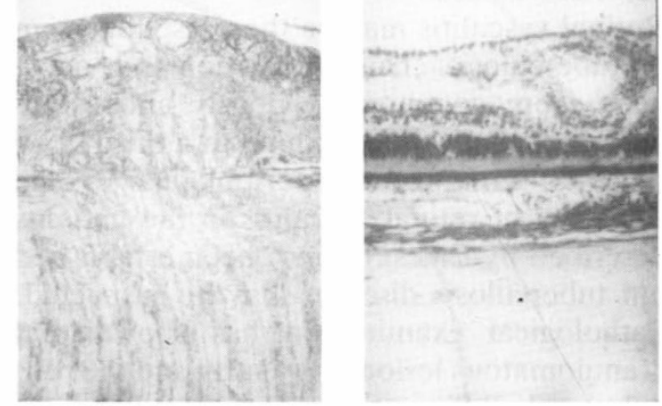

(c) right

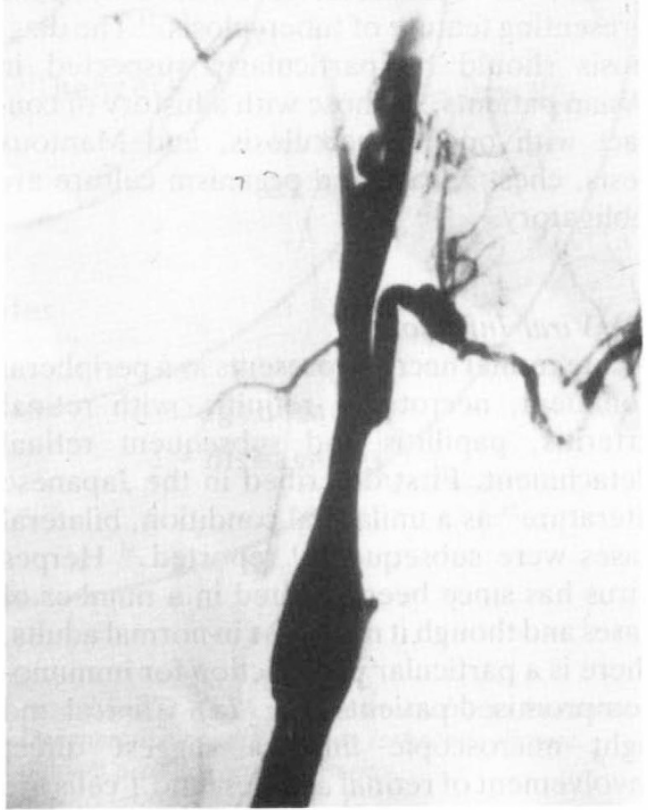

(d) right 
modulating the cerebral endothelial cell has recently been established, ${ }^{33}$ and a similar function may be ascribed to Mullers cell in the retina. In certain cases where widespread retinal vascular leakage is a feature and cells are found in the vitreous and in the absence of pigmentation the differential diagnosis between degenerative retinal and inflammatory disease may be difficult (Fig. 2b). Both groups may respond to systemic steroids, but in our experience the visual field loss is of greater magnitude in retinitis pigmentosa, and pigmentation is lacking in inflammatory disease.

\section{(c) Malignant Disease}

In any patient over the age of 50 years with bilateral uveitis and retinal vasculitis, malignant disease should be suspected. Non-metastatic, remote effects of cancer occur in cerebellar degenerative, brain stem encephalitis, motor nerve degeneration, peripheral nemopathy and myasthenic syndromes. A similar degeneration involving the retina has been described ${ }^{34}$ and further reports have suggested an immunological mechanism. ${ }^{35}$ Ocular features include reduced visual function, a diminished electroretinogram, attenuation of the retinal arterioles and diffuse leakage on fluorescein angiography (Fig. 2c). Histological studies show infiltration of the retina with inflammatory cells and perivascular cuffing. The condition is usually bilateral. Antibodies to normal retina have been shown by immunofluorescent complement fixation, ${ }^{36}$ and these may be specific to carcinoma.

Another condition which presents with bilateral uveitis, and retinal infiltrates is primary intraocular reticulum cell sarcoma or malignant lymphoma. Ocular diagnosis depends on clinical suspicion and the pro- curement of histological tissue either by pars plana vitrectomy or choroidal biopsy. The majority progress to intracranial involvement and rapid resolution is obtained with radiotherapy.

\section{(d) Retinal Ischaemia}

Ocular hypoxia may produce a cellular response in the anterior chamber which resembles iritis. ${ }^{37}$ Retinal changes include haemorrhages and infarcts, collateral vessels, microaneurysm formation and capillary nonperfusion. ${ }^{38}$ Diffuse leakage from capillaries and cells in the anterior chamber and vitreous mimic inflammatory disease. Alterations in ophthalmodynamometry readings and intraocular pressure should raise the possibility of proximal arterial disease. Carotid occlusive disease is seen in elderly patients, whilst Takayasu's disease should be suspected in younger patients (Fig. 2d).

\section{Rare Causes of Retinal Vasculitis}

\section{(1) Retinal Vasculitis in HLA-B27}

Retinal vasculitis was found in association with HLA-B27 haplotype in 9 patients, and in 5 patients ankylosing spondylitis was present. Mild peripheral vasculitis was the most common finding (Fig. 3a), though in some patients visual loss was severe with associated retinal detachment.

Visual results in these 5 cases are recorded:

\begin{tabular}{|c|c|c|c|}
\hline \multicolumn{4}{|c|}{ Right eye Left eye } \\
\hline Case 1 & $6 / 5$ & $6 / 6$ & \\
\hline Case 2 & $6 / 18$ & $6 / 6$ & Macular oedema \\
\hline Case 3 & $6 / 18$ & $6 / 12$ & Macular oedema \\
\hline Case 4 & $6 / 6$ & $\mathrm{CF}$ & $\begin{array}{l}\text { Retinal } \\
\text { detachment }\end{array}$ \\
\hline Case 5 & $\mathrm{CF}$ & CF & $\begin{array}{l}\text { Macular oedema } \\
\text { and Retinal } \\
\text { detachment }\end{array}$ \\
\hline
\end{tabular}

Fig. 2. Differential Diagnosis of Retinal Vasculitis

(a) Infective conditions. retinal vasculitis with viral retinopathy of AIDS.

(b) Degenerative. Tapeto-retinal dystrophy with night blindness, constricted fields and leakage from retinal vessels on fluorescein angiography.

(c) Malignant Disease. Cellular activity in the anterior chamber and vitreous are accompanied by visual loss and fluorescein leakage (left). Post mortem showed non-metastatic infiltration of retina, retinal vessels and optic disc (right) due to an oat cell carcinoma of the lung.

(d) Ischaemic Disease. Dilatation of capillaries, new vessels at the posterior pole and peripheral capillary closure were seen in a patient with Takayasu's disease (left). Carotid angiogram showed internal carotid occlusion (right). 


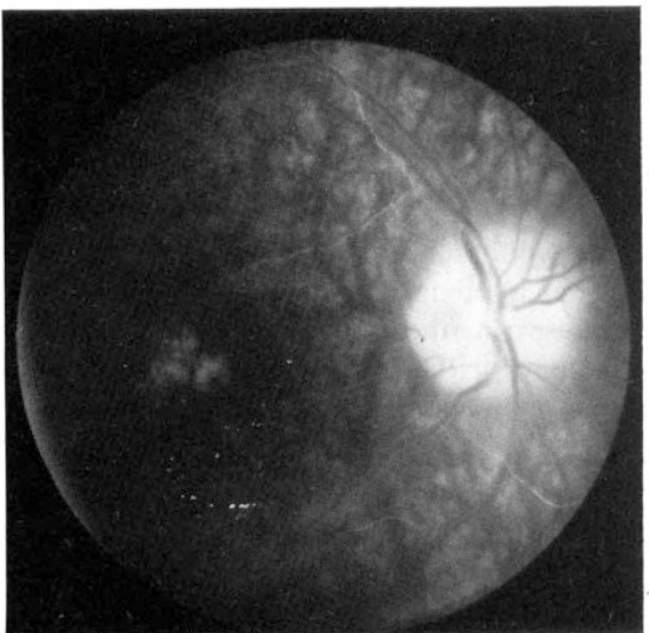

(a)

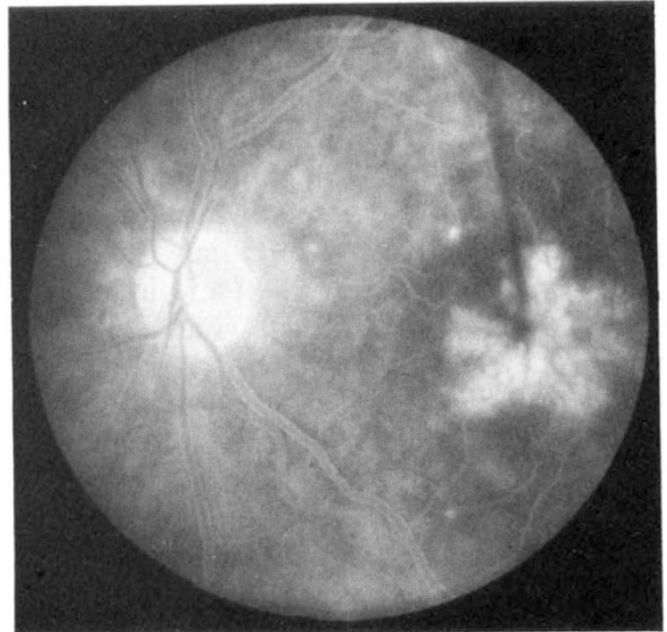

(b)

Fig. 3. Rare causes of Retinal Vasculitis

(a) HLA B27 Retinal Vasculitis

Mild cystoid maculopathy and low grade disc oedema were seen in a patient with ankylosing spondylitis.

(b) Multiple Sclerosis

This patient had a long history of visual deterioration and neurological symptons. MRI scanning showed multiple focal lesions and fluorescein angiography shows chronic cystoid macular oedema, peripheral perivasculitis was also seen.

The frequency of HLA-B27 in patients with acute anterior uveitis varies from 84 per cent in Finland to 18 per cent in Japan, and the visual prognosis is usually better in patients with anterior uveitis without HLA-B27. ${ }^{39}$ Retinal vasculitis is rarely reported in association with HLA-B27. This group is therefore of some interest, and in particular is the main group in our series to manifest non-rhegmatogenous retinal detachment.

\section{(2) Multiple Sclerosis}

Sheathing of the retinal veins in multiple sclerosis was first described by Rucker $^{40}$ from the Mayo Clinic and his observations have been confirmed both clinically and pathologically. Rucker noted similar changes in the retina to those occurring in the CNS and thought this suggested the basic lesion in multiple sclerosis was phlebitis. A recent pathological study found lymphocytic or granulomatous periphlebitis in 4 cases from 47 autopsy studies and suggested this was the result of an immune response in the nervous system, from either an exogenous or endogenous antigen. ${ }^{41}$ The incidence of peripheral sheathing is not related to disease severity or duration. In some cases the retinal changes may be severe (Fig. 3b) with extensive capillary closure and new vessel formation leading to vitreous haemorrhage.

In 150 cases of retinal vasculities in this report 11 patients were found to have retinal vasculitis and neurological involvement.

Retinal features included:

$\begin{array}{ll}\text { Peripheral sheathing } & 5(45 \%) \\ \text { Anterior uveitis } & 4(36 \%) \\ \text { Haemorrhages } & 4(36 \%) \\ \text { New Vessels } & 3(27 \%)\end{array}$

Diagnostic criteria are often speculative however, as it may be hard to differentiate between sarcoidosis and multiple sclerosis. In our series of sarcoid patients in this study 12 per cent had neurological involvement.

\section{Retinal Arterial Involvement: Retinal Arteritis}

Retinal arterial occlusion without detectable embolisation has been noted for many years, but an increase in the number of reports has occurred over the past few years. An idiopathic group has emerged under a number of terms, including: retinal arteriolitis ${ }^{42}$ retinal 
periarteritis, ${ }^{43}$ recurrent artery occlusion..$^{44}$ Microangiopathy of the brain and retina ${ }^{45}$ indicates concurrent cerebral involvement, and deafness has also been associated. ${ }^{46}$ In all these reports there was major involvement of retinal arteries and arterioles but with preserved central vision and an absence of inflammatory response in the eye (i.e. absence of cells in the anterior chamber or vitreous). Debate therefore exists as to whether these changes represent immune complex deposition or deposition of antigen in the vessel with secondary antibody reaction. Interaction between platelets and endothelial cells may be altered and recently antibodies to endothelial cells and platelets have been detected. These patients present a clinical diagnostic problem, and examples are given with discussion of the mechanism. In addition arteriolar occlusions have been described in association with systemic disease of proven autoimmune nature and these will also be considered.

\section{Wegener Granulomatous and Polyarteritis Nodosa}

It is probable that these two conditions represent different clinical spectrums of the same disease. In 1866 Kussmaul and $\mathrm{Maier}^{20}$ defined the gross and microscopic pathology of the disease that they appropriately named periarteritis nodosa. The term periarteritis nodosa described the nodules in the media or adventitia of small arteries. The findings of epitheloid and giant cells and a propensity to allergic manifestations such as asthma led Churg and Strauss $^{23}$ to introduce the term allergic granuloma. Zeek ${ }^{47}$ suggested the term necrotising angiitis for this group and suggested five subgroups:

(1) Hypersensitivity angiitis

(2) Allergic granulomatous angiitis

(3) Rheumatic arteritis

(4) Periarteritis nodosa

(5) Temporal arteritis

Wegener in $1936^{48}$ defined a disease characterised by necrotising granulomatous vasculitis of the upper and lower respiratory tract progressing to renal involvement with glomerulonephritis. This condition has been further subdivided into several different subgroups, one of which has granulomatous fea- tures, e.g. sarcoidal Wegeners, and another with lymphoreticular features, e.g. Lymphomatoid granulomatosis.

The proximity of the orbit to the upper nasal tract may account for the high incidence of ocular involvement in patients with Wegeners granulomatosis: Ocular involvement occurrred in 47 per cent of the patients described by Haynes and others, ${ }^{49}$ with orbital involvement being most common, and only one patient having optic disc vasculitis. A review of 8 patients with ocular involvement seen at St Thomas' Hospital showed retinal involvement in only one case and this case represented the rare group of sarcoidal Wegeners. The patient was a twelve year old boy presenting with transverse myelitis, pneumonia and uveitis. The retinal veins show perivasculitis in the periphery and there was no arterial involvement. ${ }^{30}$ The retinal involvement in this case resembles the retinopathy of sarcoidosis and this is consistent with the histological similarity to sarcoidosis.

Ocular involvement in periarteritis nodosa is extremely rare and my experience extends to only two cases which are included in this group. In one patient bilateral sixth nerve palsy was accompanied by branch arteriolar occlusions. In the other patient a central vein occlusion was the only ocular manifestation.

\section{Systemic Lupus Erythematosus}

Systemic Lupus Erythematosus (SLE) is a well established non-organ specific autoimmune disease and both human and animal studies suggest that genetic, endocrine and environmental factors are involved.

Retinal involvement occurs in 5 to 10 per cent of cases and this association provides strong evidence to support the concept of autoimmune disease producing a retinopathy. SLE produces multisystem involvement and definitive criteria are available with the detection of extractable antinuclear antibodies, and in particular anti DNA antibodies.

The retinal features are due to arterial occlusion (Fig. 4a) and the characteristic findings are cotton wool spots (Plate 1a), larger retinal infarcts and optic disc infarction. Embolic occlusion from cardiac vegetations may occur, but the retinal changes are usually manifest without clinical or post mortem 


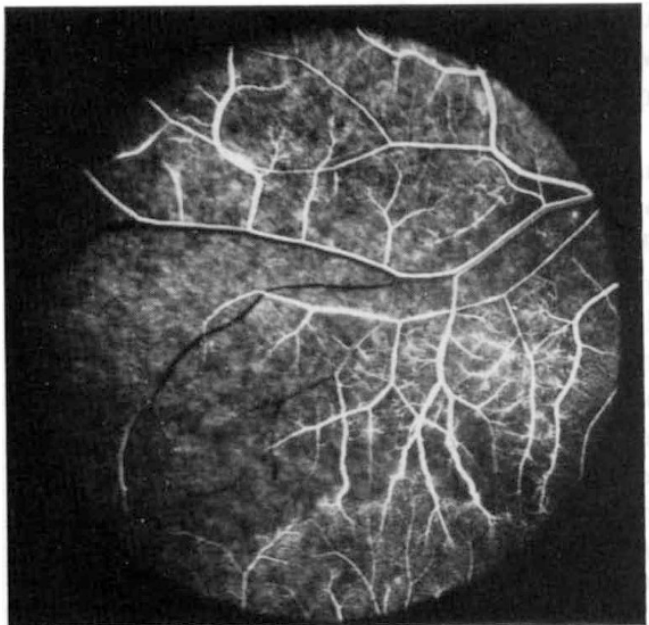

(a)

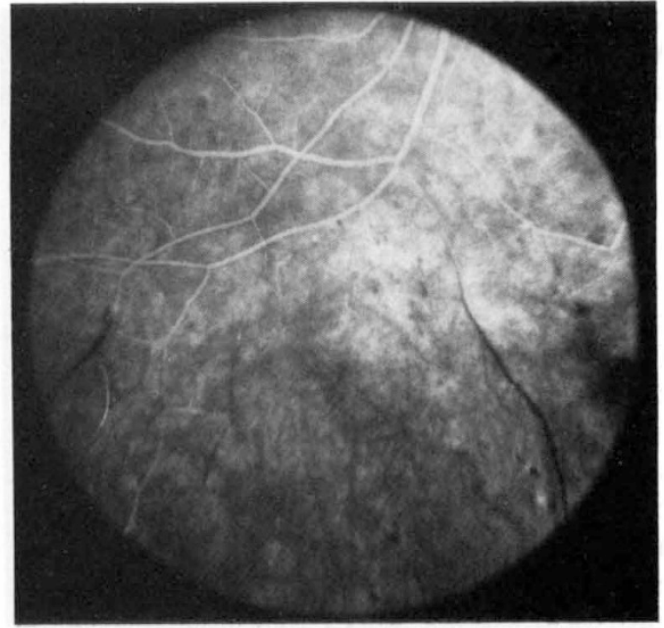

(b)

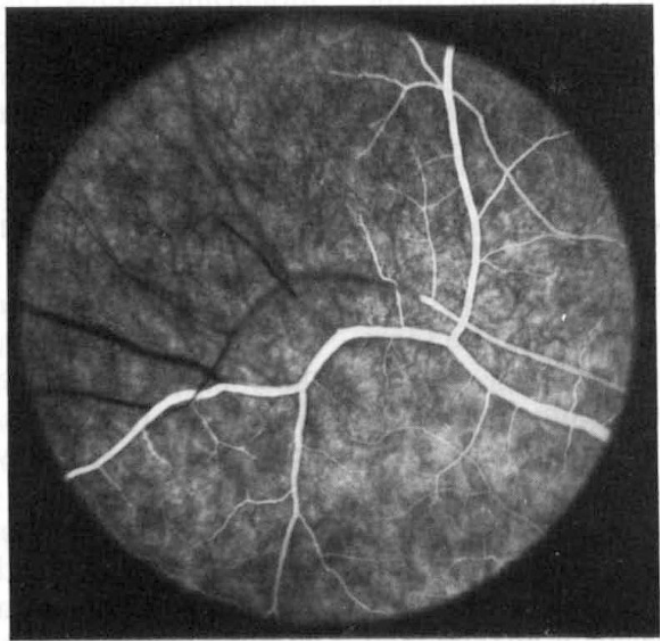

(c)

Fig. 4. Retinal Arteritis

(a) Systemic Lupus Erythematosus

Arterial attenuation was visible in the supro-temporal artery on fluorescein angiography in a patient with SLE (left). There is peripheral occlusion of the retinal arterioles with reduced retinal perfusion.

(b) Loefflers Syndrome

Multiple focal anteriolar occlusions were present in both eyes of a 35 year old man with spared central vision.

(c) Idiopathic

Retinal arteriolar occlusion on fluorescein angiography in a 35 year old man without any systemic disease. Multiple arteriolar occlusions were visible in each eye.

changes of Libman-Sachs endocarditis, and without visible retinal emboli.

A particular feature of the retinopathy of SLE is that the veins are not involved, and there are no inflammatory changes in the anterior chamber or vitreous. Pathological examination shows occlusion of arterioles by fibrinoid material without vasculitis, though vasculitis or immunoglobulin deposition may be found in other vessels.

In cerebral SLE microvascular damage is a characteristic neuropathologic finding and speculation suggests two immunopathogenic mechanisms. Firstly, immune complex mediated vascular injury and secondly direct autoantibody-mediated attack on the vascular 


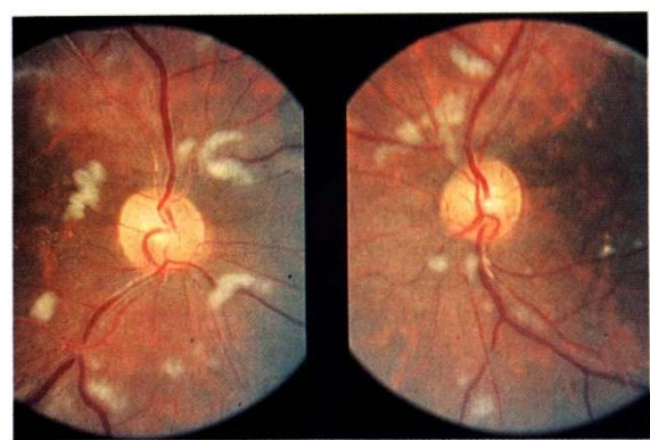

(a)

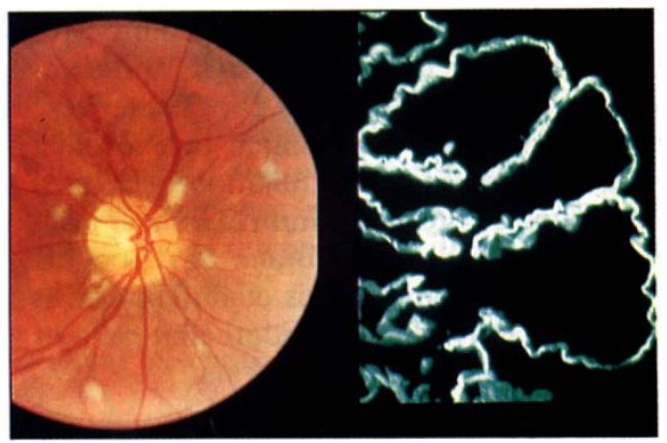

(b)

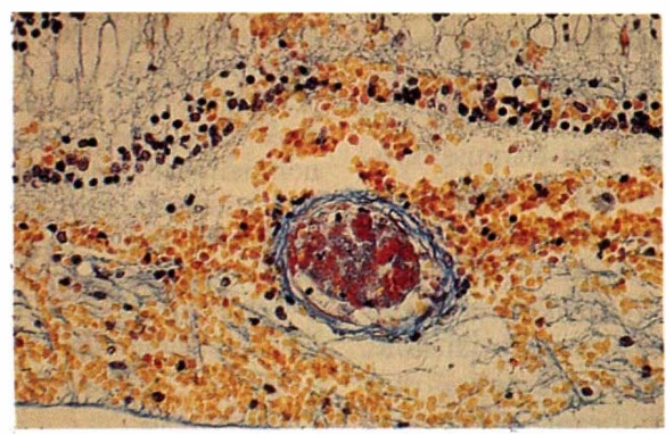

(c)

Plate I. Retinal Arteritis

(a) Systemic lupus erythematosus with bilateral retinal cotton wool spots.

(b) Goodpastures Syndrome. Multiple cotton wool spots were seen in each eye and renal biopsy confirmed the diagnosis and showed the linear deposition of IgG.

(c) Loefflers Eosinophilic Syndrome. Multiple retinal artery occlusions were visible clinically and histological examination showed fibrinoid thrombus in the retinal artery without signs of cellular infiltration (Mallory stain).

endothelium. The cross reactivity of anticardiolipid antibodies with cell membrane phospholipids may suggest an explanation for the endothelial cell damage, as high levels of anticardiolipid antibodies are a feature of some cases of SLE. ${ }^{50}$

A third and particularly interesting aspect is finding of antibodies to neuronal membrane antigens, which may be shared with lymphocyte antigens. In one patient in this series pathological examination of the eyes was obtained from a young boy with cerebral and ocular SLE. Fibrinoid occlusion of retinal arteries occurred without arteritis, but extensive cellular infiltration and vasculitis occurred in choroidal vessels. The choroidal inflammatory signs may reflect the increased permeability of the choroidal vessels, as a result of immune complex disease involvement and cerebral arteries showed occlusion though an arteritis was found in the meningeal vessels. ${ }^{51}$

\section{Goodpastures Syndrome}

Goodpastures in $1919^{52}$ described a patient with haemoptysis, anaemia and proteinuria, and post mortem examination showed pulmonary alveolar haemorrhages and glomerulonephritis. Immunological studies have shown the deposition of immunoglobulin $\mathrm{G}(\mathrm{IgG})$ in a linear pattern in basement membrane of the kidney and lung. Similar changes were reported in the eye by Jampol et al. ${ }^{42}$ with linear deposition of IgG in Bruchs membrane and the basement membranes of the choroidal vessels. Clinical examination of the two patients he reported showed ischaemic areas in the choroid in one, and both had non-rhegmatogenous retinal detachments. I have seen one case of Good- 
pastures Syndrome who was normotensive but had multiple cotton wool spots and occasional haemorrhages ${ }^{8}$ (Plate $1 \mathrm{~b}$ ). There were no signs of retinal detachment or choroidal disease. Histological examination of a renal biopsy showed IgG deposition in a linear fashion in the basement membrane. It is possible that the retinopathy in this condition also is related to antibodies to endothelial cells or constituents of the cell membrane.

\section{Churg Strauss Syndrome}

Allergic angiitis and granulomatosis forms part of the spectrum of disseminated systemic necrotising vasculitis and pathological examination shows fibrinoid necrosis of small and medium sized arteries. Churg Strauss syndrome differs from polyarteritis nodosa in the degree of inflammatory involvement of small vessels including capillaries and veins. There are several reports of ocular involvement in this syndrome, and retinal arterial occlusions have been a feature. ${ }^{53.54}$ It is interesting that there is a marked peripheral and tissue eosinophilia in the Churg Strauss Syndrome which is also a feature of the hypereosinophilic syndrome.

\section{Loefflers Eosinophilic Syndrome}

An interesting young patient with endocarditis, eosinophilia and renal disease was referred to us by Dr. Guy Neild. Fundus examination showed numerous retinal arterial occlusions in both eyes without signs of retinal infarction (Fig. 4b). Fluorescein angiography confirmed arteriolar occlusion, and there was no evidence of choroidal involvement. Autopsy was performed which showed occlusion of arterioles by fibrinoid material but without perivascular inflammation (Plate 1c). The patient was diagnosed as Loefflers fibroplastic endocarditis which represents one end of the spectrum of the hypereosinophilic syndrome. ${ }^{55}$

\section{Idiopathic Retinal Arteritis}

The combination of multiple retinal artery occlusions in young patients often with additional neurological involvement has been repeatedly described over the past decade. ${ }^{42,44,45}$ This syndrome has not evolved into a nosological or aetiological entity. A typical case is illustrated below:

A 40 year old cigarette smoking surgeon was admitted to the National Hospital under Dr. W. Goody. He had multiple peripheral non-embolic retinal artery occlusions in both eyes (Fig. 4c), central vision was spared. There was no evidence of inflammation and cotton wool spots were not seen. Extensive investigations haematologically and immunologically were normal, though lipid levels were slightly increased. Macroangiography of the cerebral vessels showed no occlusive arterial disease, no angiitis and no source for embolisation in the carotid arteries. Similarly, echocardiography showed no source for cardiac embolisation.

Progress: Over the next year, the patient developed areas of neovascularisation at the border of non-perfused and perfused retina, which gave rise to vitreous haemorrhages. These areas of neovascularisation were treated by laser photocoagulation.

No systemic disease evolved over 5 years of follow-up examinations.

\section{Pathogenesis}

A group of conditions therefore exists presenting in normotensive patients without a source for embolisation in which retinal and cerebral infarction occurs. The conditions include SLE, PAN, Churg Strauss Syndrome, Goodpastures Syndrome and Loefflers Eosinophilic Syndrome, with an additional idiopathic group. The clinical features of this group are:

(1) Cotton wool spots indicating precapillary arteriolar involvement.

(2) Retinal branch arteriolar occlusions

(a) With infarction

(b) Without signs of infarction, suggesting that patients were not examined during the acute phase, or that evolution of occlusion was chronic in nature.

(3) No signs of ocular inflammation were present on examination.

(4) Similar features could occur in the cerebral circulation.

It is interesting to speculate that this group may exhibit antibodies or autoantibodies against endothelial cells or constituents of their cell membranes with immune complex deposition. It is established that retinal and 
cerebral endothelial cells have similar anatomical and physiological characteristics and this may extend to their immunological properties. In addition the finding of antineural antibodies in cerebral SLE raises the question of whether shared antigens occur in the retina and brain. The assumed autoimmune nature of the associated disease lends credence to the view that this is an immunological process and though a true vasculitis is not seen on histological examination the mechanism is presumably inflammatory. The classification of this group has been neglected and I would like to suggest the term 'retinal arteritis' until the precise mechanisms are more fully established.

\section{Autoimmune Retinal Vasculitis}

\section{Terminology}

Autoimmunity represents an immune response directed against the host which may become a pathological factor if it exceeds a certain threshold.

Certain criteria are necessary for establishing an autoimmune disease:

(1) Autoreactive antibodies or lymphocytes can be detected.

(2) The autoimmune reaction can be shown to damage target cells directly or by secondary immunological and inflammatory reactions.

(3) The disease can be transmitted by autoantibodies.

(4) Immunomanipulation ameliorates the disease.

Many of these criteria are established in retinal vasculitis and in addition we have developed an animal model of the disease which closely simulates the disease in man on immunological, clinical and pathological grounds.

\section{Systemic Diseases}

Autoimmune mechanisms play a prominent role in the retinopathy of SLE, Goodpastures Syndrome and polyarteritis nodosa, and these all represent well established autoimmune diseases. Autoimmunity also plays a part, possibly as an epiphenomenon, in sarcoidosis, Behçet's Syndrome and HLA-B27 uveitis. Thus autoimmunity may have a central role in many of the conditions that produce retinal vasculitis. Retinal autoimmunity may be demonstrated by indirect immunofluorescent techniques to be present in cases of retinal vasculitis. In addition, the presence of cellular immune responsiveness exists to a purified retinal antigen in patients with ocular inflammatory disease. ${ }^{56}$

\section{Retinal Vasculitis with Systemic Disease}

\section{Sarcoidosis}

Sarcoidosis is a multisystemic granulomatous disorder of unknown aetiology with pulmonary, cutaneous and ocular manifestations.

Diagnosis depends on identifying the multisystem disease, and biopsy material containing non-caseating granulomas, with epitheloid cells, giant cells and macrophages. Speculation exists that sarcoidosis begins in the respiratory system because pulmonary involvement is found in almost 90 per cent of cases. The Kviem test and alveolar lavage provide diagnostic confirmation, though lymphopenia, elevated SACE and calcium abnormalities are suggestive. There is a depression in cell mediated immunity manifested by a reduction in the number of circulating $T$ cells and impaired responses of these cells to polyclonal mitogens and recall antigens. There is also heightened B-cell activity with elevated serum immunoglobulins and the presence of autoantibodies and circulating immune complexes.

Ocular involvement occurs in approximately 25 per cent of cases. ${ }^{57,58}$ The ophthalmologist by detecting ocular involvement may aid the diagnosis of a multisystem disease, but furthermore the retinal findings may be pathognomonic. ${ }^{59}$ In the present series there were 17 biopsy proven cases of sarcoidosis. In this group in addition to pulmonary and ocular involvement the following systems were involved:

$\begin{array}{lr}\text { Arthritis } & 7 \\ \text { Cutaneous } & 2 \\ \text { CNS } & 3 \\ \text { Kviem + wi } & 10 \\ \text { Biopsy Lung/Skin } & 7\end{array}$

Retinal involvement was characterised by focal periphlebitis (Fig. 5) and this is a characteristic feature of sarcoidosis (Plate 2a). Pre- 


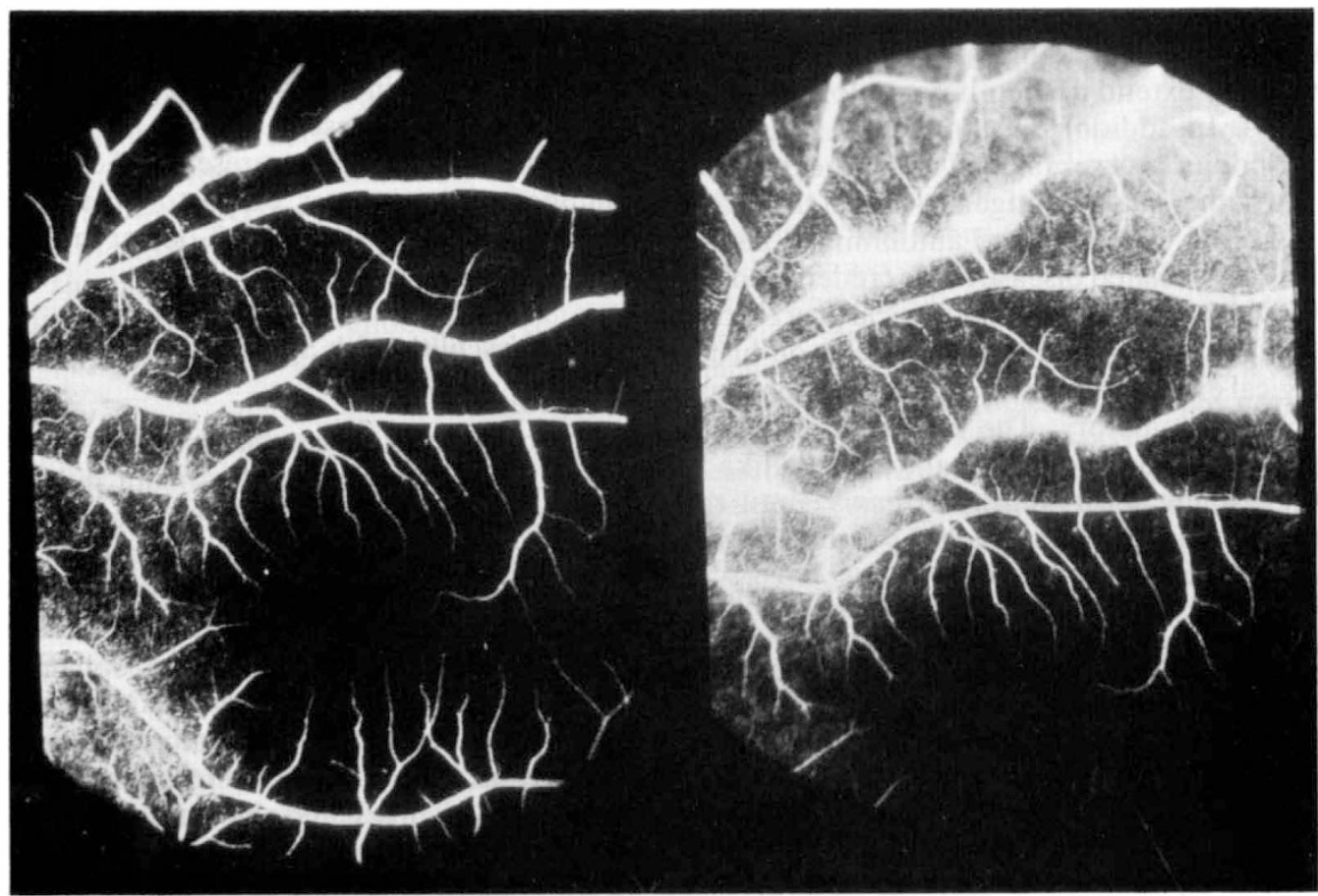

Fig. 5. Sarcoidosis

Focal Periphlebitis: Multiple focal areas of perivenous leakage were seen on fluorescein angiography, in a patient with histologically proven sarcoidosis (left). Prompt resolution occurred within a month on high dose steroids (right).

dominant changes occur around the veins and arterial involvement is virtually never seen.

Clinical and fluorescein angiographic features include:

(1) Focal periphlebitis (78\%)

(2) Diffuse capillary leakage $(44 \%)$

(3) New vessel formation (5\%)

(4) Acute retinopathy

Iritis occurred in 41 per cent of cases and retinal and optic disc involvement may occur without involvement of the anterior chamber. Retinal vein occlusion and infiltration of the retina are not seen in sarcoidosis and serve to differentiate sarcoidosis from Behçet's disease.

There were no cases of the acute retinopathy of sarcoidosis in this series though this rare presentation has been seen in two other cases and included in other reports. ${ }^{30,59}$ The acute retinopathy usually progresses to capillary closure and neovascularisation.

\section{Behçet's Syndrome}

Behçet's Syndrome is a multisystemic disease affecting young adults with a classical traid of mouth ulcers, genital ulcers and iritis. Recognised in the writing of Hippocrates but eventually names after a Turkish dermatologist, Professor Halusi Behçet; this condition provides a major challenge to ophthalmology because of the ocular devastation it produces.

Clinically patients give a long history of mouth ulcers, usually from childhood, and often with up to 12 ulcers occurring simultaneously. Ocular features present in the 2nd and 3rd decades and in addition to ocular features there are mucocutaneous, intestinal, vascular, urological and neurological manifestations. Death from Behçet's Syndrome is rare ( 3 to 4 per cent) and the disease usually burns itself out, leaving a blind or partially sighted patient.

The underlying histopathologic lesions in all organ systems is vasculitis. This includes perivascular infiltrates of mononuclear cells, swelling and proliferation of endothelial cells leading to partial obliteration of small vessels and fibrinoid degeneration. ${ }^{60}$ Despite a wide 


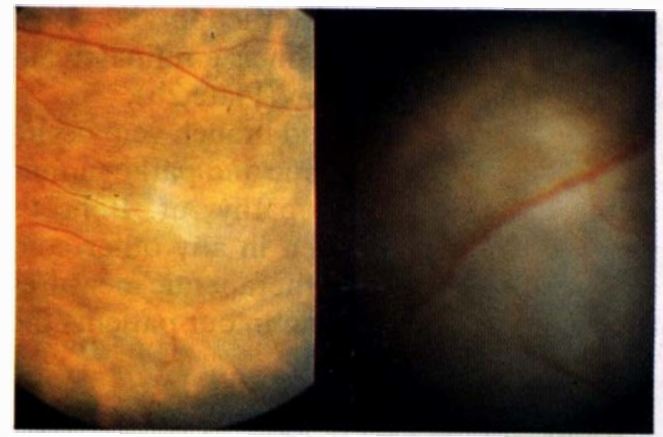

(a)

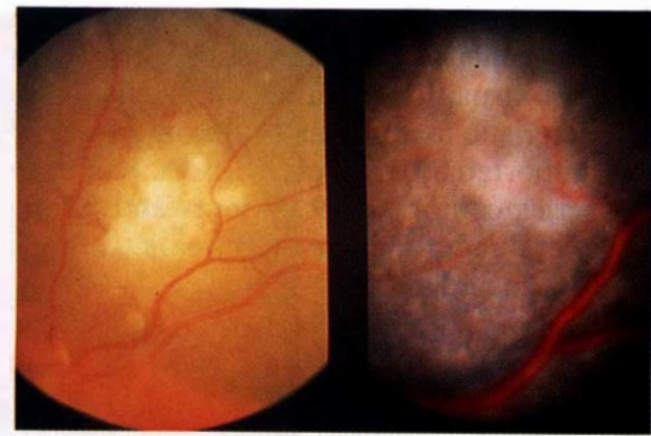

(b)

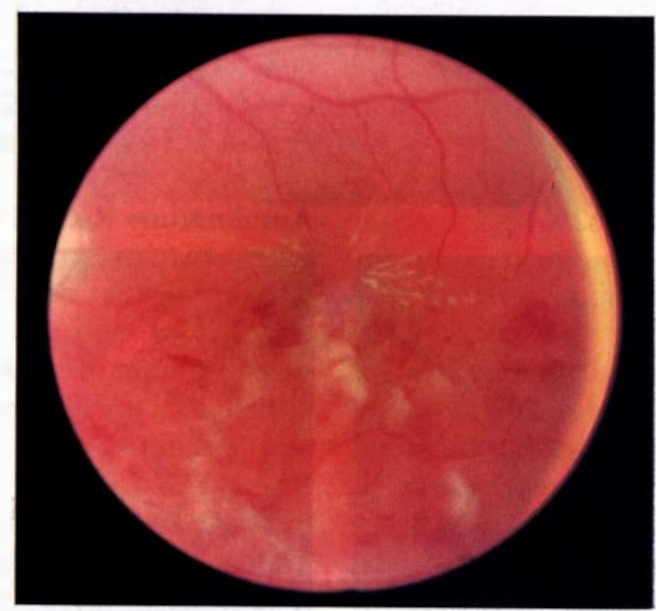

(c)

Plate II. Retinal Vasculitis with Systemic Disease

(a) Focal periphlebitis in a patient with sarcoidosis (left) and on the right focal periphlebitis in the rat model.

(b) Retinal infiltration in a patient with severe Behçet's disease and on the right severe retinal infiltration is seen in the Black-hooded Lister rat.

(c) Retinal Venous Occlusion in Behçet's disease. The only group of retinal vasculitis with a propensity to venous occlusion was Behçet's disease, with cotton wool spots and exudates at the macula.

variety of immunological abnormalities, there is no specific diagnostic test and the clinician rather than the immunologist holds the key to diagnosis. The high incidence of the haplotype HLA B5 has been described in all epidemiological studies of ocular Behçet's, including those in Japan and Europe. HLAB27 however may be found in the arthritic type of Behçet's Syndrome and HLA-B12 in the mucocutaneous type. ${ }^{61}$ There may be a disequilibrium linkage between HLA-B5 and HLA-A2 in the ocular group with retinal vein occlusion. ${ }^{62}$ Immune complexes are found in patients and in exacerbations of disease an increased IgG and IgM is found but a decrease in IgG complexes. ${ }^{61}$
Ocular involvement has certain specific and diagnostic features, and occurs in 80 per cent of patients. Behçet's Syndrome produces the most aggressive pattern of vasculitis and in the last decade vision was deemed to be lost within 3.36 years after onset of ocular involvement. ${ }^{63}$ However, the prognosis has been improved by early recognition and aggressive treatment by steroids, immunosuppressives and cyclosporins. Excellent reviews are available ${ }^{60,64}$ so that this discussion will concentrate on the retinal features.

Emphasis must first be placed on the fact that this is a retinal and not a choroidal disease, on both clinical and pathological evidence. Hypopyon is a rare feature occurring 
in our series in 13 per cent of cases, and iritis (48 per cent) is mild and does not usually produce visual loss. Retinal involvement has characteristic features first indicated in $1979^{\circ}$ but supported by the present series. Our present series comprises 39 patients and 65 per cent were under the age of 40 years. General features included:

$\begin{array}{lr}\text { Mouth ulcers } & 100 \% \\ \text { Genital ulcers } & 66 \% \\ \text { Skin lesions } & 51 \% \\ \text { Arthritis } & 46 \% \\ \text { Thrombophlebitis } & 43 \% \\ \text { CNS involvement } & \end{array}$

The ocular features could be subdivided into three distinct groups:

(1) Diffuse capillary leakage $(100 \%)$

(2) Branch vein occlusion (62\%)

(3) Infiltrations (40\%)

(4) Terminal stage with optic atrophy and macular degeneration

Diffuse capillary leakage occurred in all cases, as observed by fluorescein angiography and affected the posterior pole. Maximal involvement occurred at the disc, the arcuate capillaries and the macular capillaries (Fig. 6a). A peripheral periphlebitis, or focal periphlebitis was not seen. Extensive areas of retinal non perfusion were not seen without venous occlusion, and neither was neovascularisation a feature. These factors serve to distinguish the retinopathy of Behçet's Syndrome from other types of vasculitis.

Branch vein occlusion occurred in 62 per cent of cases and could involve small macular vessels or hemisphere vein occlusion. Central retinal vein occlusion was not seen. Factors contributing to the pathogenesis include inflammation of the vessel wall but in addition elevated blood viscosity was found in 2 patients with elevated whole blood viscosity and fibrinogen levels. Branch vein occlusion particularly when the macular vessels are involved, provides a major source of the visual disability associated with Behçet's Syndrome.

Retinal infiltration presents deep pale areas, often surrounded by haemorrhages (Fig. 6b). They resolve promptly on steroid treatment suggesting they are manifestations of inflammation rather than ischaemia. They are a cause of retinal destruction and visual morbidity and may be seen as a retinal manifestation of the hypopyon (Plate $2 b$ ).

Retinal infiltrations and branch vein occlusions (Plate 2c) are specific and pathognomic features of the retinopathy of Behçet's Disease and are not seen in any other condition. Despite modern therapeutic measures and the use of cyclosporin in our patients the visual prognosis was bad.

45 per cent $<6 / 18$ in both eyes

80 per cent $<6 / 18$ in one eye

Immunological tests were not of diagnostic value, though HLA-B5 occurred in 65 per cent of cases and in 27 per cent of cases the combination HLA A2 and B5 were present in branch vein occlusions.

\section{Autoimmune Retinal Vasculitis}

Sixty-seven patients had retinal inflammatory disease without other systemic features. The findings of autoimmune features and the establishment of an animal model justifies the appellation for this group of 'autoimmune retinal vasculitis'.

\section{Features of Autoimmune Retinal Vasculitis}

There were 67 patients in this group with a female preponderance ( 27 males, 40 females). The majority ( 72 per cent) of patients were under 40 years of age.

$$
\begin{aligned}
& \text { Age }<20 \\
& \text { 20-29 } \\
& 21 \% \\
& \text { 30-39 } \\
& \text { 40-49 } \\
& 21 \% \\
& 30 \% \\
& >50 \\
& 15 \% \\
& 13 \%
\end{aligned}
$$

Examination showed no evidence of cutaneous, neurological or pulmonary disease and specific tests were negative. Immunological tests were similar to those patients with retinal vasculitis and a systemic disease, though the incidence of retinal autoantibodies was lower in those with systemic disease only.

Two subgroups could be demonstrated, one with positive retinal antibodies (34 patients) and the other with negative retinal antibodies (36 patients). There were no clinical differences between these groups and one may speculate that in the negative group tests may have been directed at the wrong epitope of retinal $\mathrm{S}$ antigen, or indeed the wrong antigen. 


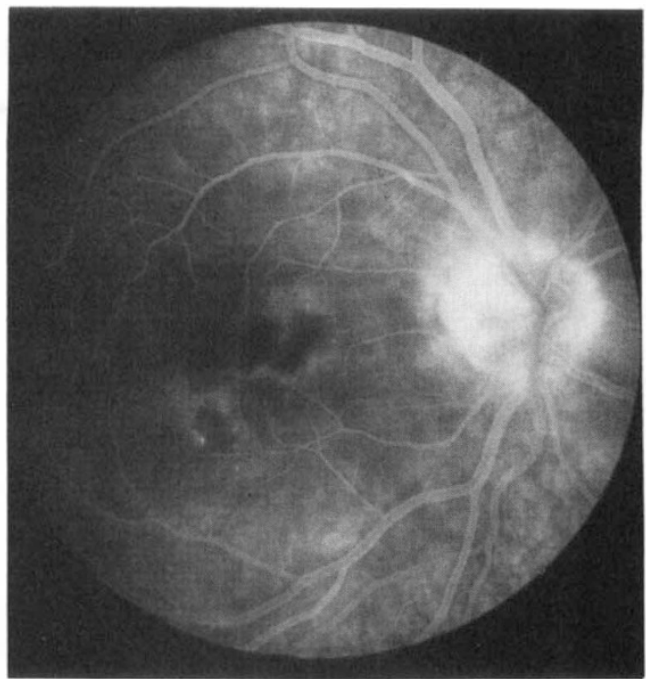

(a)

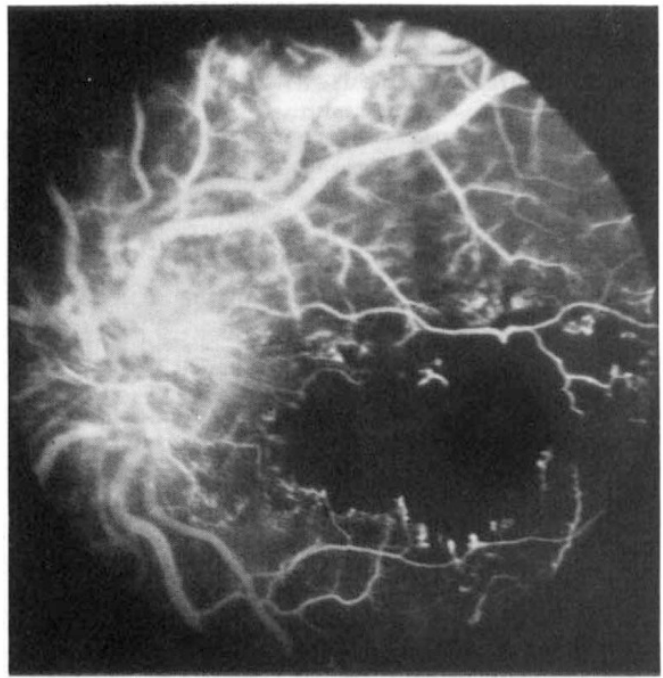

(b) left

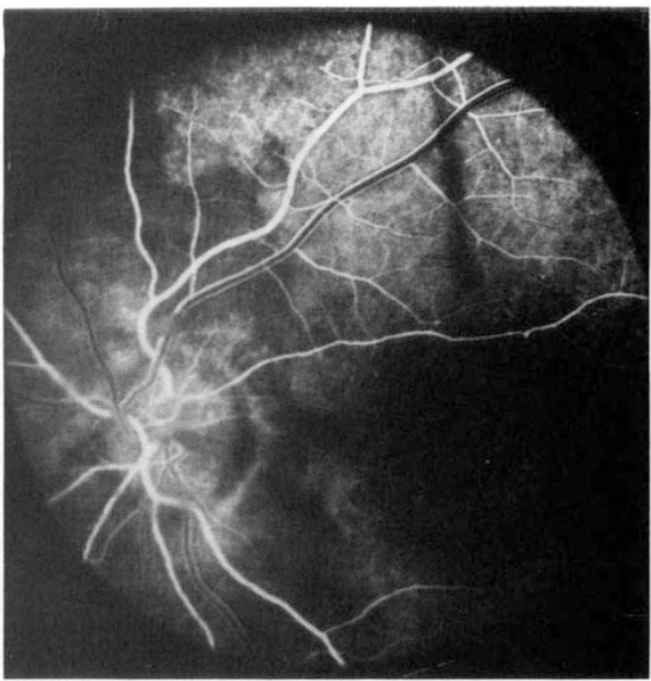

(b) right

Fig. 6. Behçet's Disease

(a) Diffuse Posterior pole leakage with Macular Infiltration

Central visual loss was due to an infiltration in the macular region. Clinical examination showed a pale deep retinal lesion and fluorescein angiography showed impaired filling of the lesion but surrounding hyperfluorescence. In addition diffuse capillary leakage from the disc and posterior pole was seen.

(b) Retinal Infiltrations

This young man with mouth ulcers was blind in one eye and had vision of 6/36 in the left eye. Diffuse dilatation of all vessels was seen with reduced perfusion of the macula due to inflammatory changes (left).

One month after after steroids and Imuran, vision had improved to 6/9 and macular perfusion was restored (right).

\section{Retinal Features}

There were two characteristic features of autoimmune retinal vasculitis:

(1) Diffuse capillary leakage (83\%)
(2) Capillary closure and new vessels (23\%) In particular there were no infiltrations or branch vein occlusions in contrast to Behçet's Disease, no evidence of peripheral 
periphlebitis as seen in sarcoidosis, and no signs of arterial occlusion. ARV therefore represents a distinct clinical entity and a typical patient is demonstrated.

This 6 year old girl was first referred in 1977 with a history of inflammatory ocular disease and no other systemic signs. Vision was $6 / 60$ in the right eye and $6 / 12$ in the left eye. Fundus examination showed extensive hard exudates over the posterior pole in both eyes (Plate III), and fluorescein angiography showed extensive capillary and venous leakage of dye (Fig. 7a) with large areas of capillary closure in the periphery (Fig. 7b). She progressed to develop bilateral vitreous haemorrhages. She was treated with laser photocoagulation and high dosage steroids. Close monitoring over the ensuring years results in vision in 1985 of $6 / 60+1$ in the right eye and $6 / 24$ in the left eye.

\section{Investigations}

Smooth muscle antibodies IgG + Igm - positive Gastric parietal cells IgG + Igm - positive

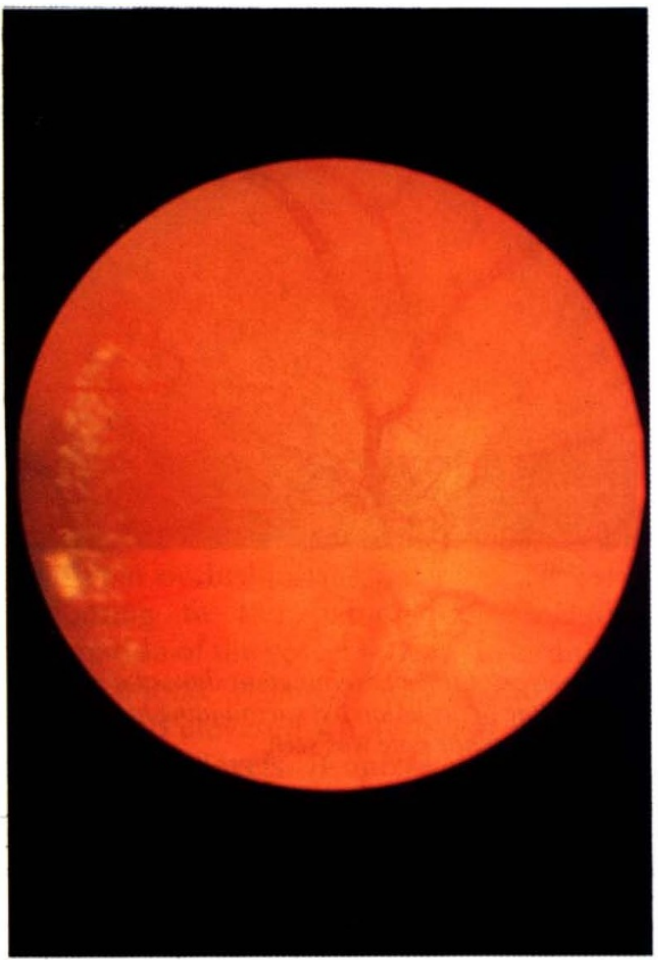

(a)
There was no evidence of circulating immune complexes, and the $\mathrm{C} 4$ level was elevated. Antiretinal antibodies were positive. HLA typing showed A1, A2, B12, B15.

In the group of patients with ARV, the following immunological abnormalities were detected:

Retinal antibodies

$53 \%$

Elevated circulating immune

$$
\text { complexes }
$$

Elevated CIC + retinal antibodies $24 \%$

Absent CIC + retinal antibodies $24 \%$

Immunoglobulins abnormal $\quad 37 \%$

IgG reduced $\quad 4 \%$

IgA elevated $\quad 21 \%$

IgM elevated $15 \%$

\section{Immunological Investigations in Retinal \\ Vasculitis}

Immunological abnormalities are present in a

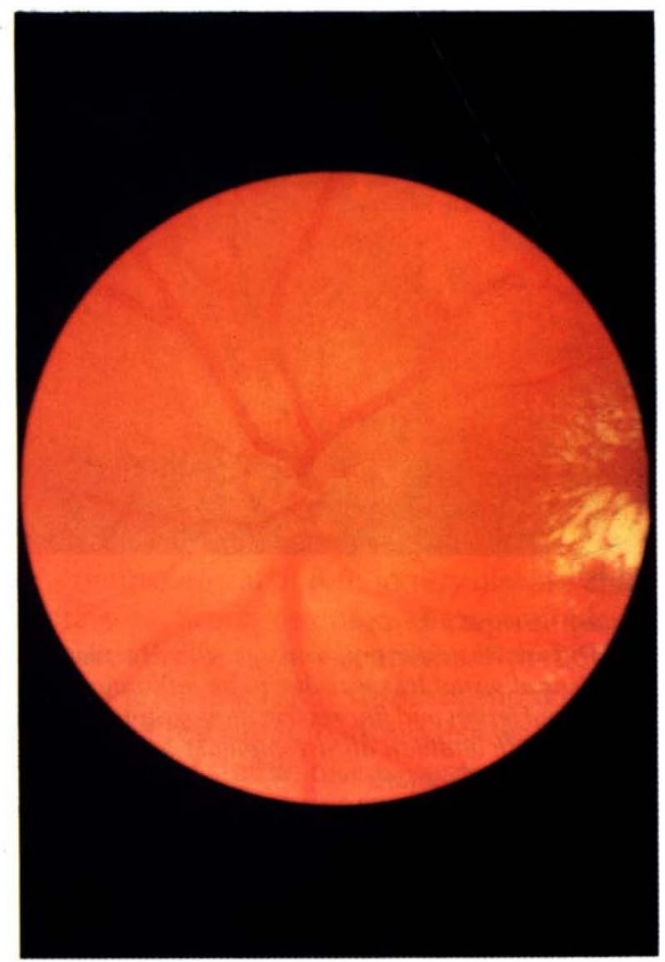

(b)

Plate III. Autoimmune retinal vasculitis

Severe visual loss occurred in both eyes of a 6 year old girl. The optic discs were grossly swollen on both sides, and dilated capillaries and new vessels were visible on the surface. An exudative retinopathy was present at the macula in both the right (a) and left eyes (b). 


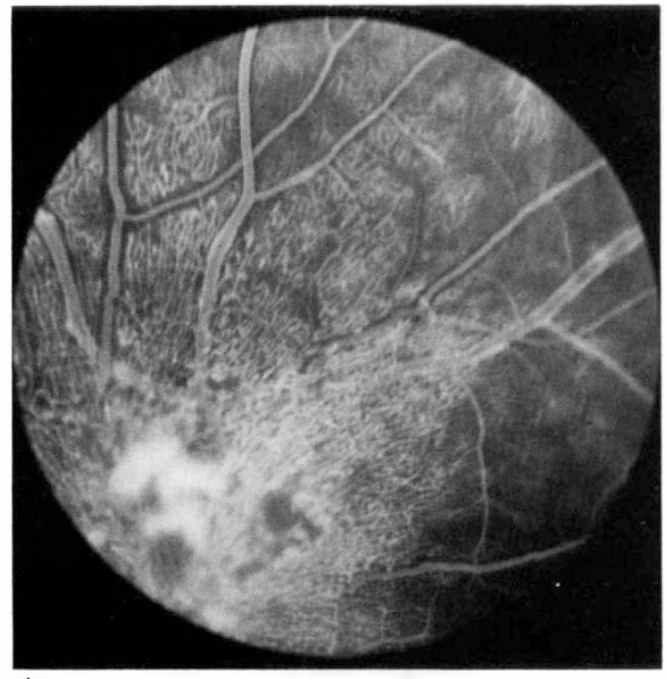

(a)

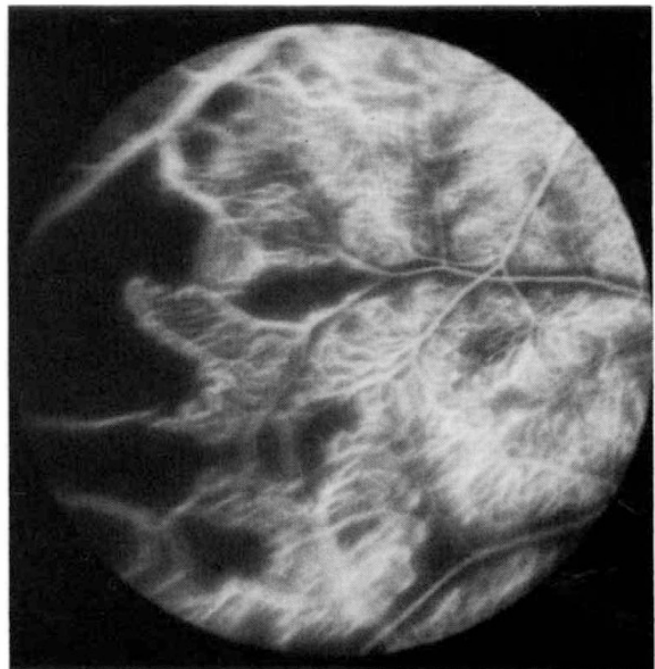

(b)

Fig. 7. Autoimmune retinal Vasculitis

(a) A 6 year old girl was seen with reduced vision in both eyes (colour Plate III). Fluorescein angiography of the left eye showed diffuse capillary dilatation and capillary leakage over the whole of the posterior pole but particularly at the optic disc. New vessels were also visible.

(b) Peripheral examination on fluorescein angiography showed dilatation of all capillaries and large areas of nonperfusion.

large number of patients with retinal vasculitis, but provide diagnostic information in the minority. Interest has therefore centered on the relationship between autoimmunity and circulating immune complexes in this group (Fig. 8). Comparisons were made with three groups:

(1) Patients with systemic disease alone

(2) Patients with systemic disease and RV

(3) Patients with RV alone

Retinal autoantibodies were found in a significantly higher proportion of patients with $\mathrm{RV}$ than in those with systemic disease alone. Immune complexes and complement abnormalities were found together in isolated RV but this association was more common with systemic disease. Study of circulating immune complexes and retinal antibodies were not helpful in distinguishing RV alone from patients with RV and systemic disease. However, patients with isolated $R V$ tended to have a negative association between the presence of CIC and titres of retinal autoantibodies. These findings led us to suggest that the formation of circulating immune complexes containing anti-idiotypic antibody may be a compensatory host response to the development of anti-retinal autoimmunity. These findings have been fully discussed previously ${ }^{65}$ and further studies have corroborated this view.

A point prevalence study indicated that a combination of high levels of retinal autoantibodies with the absence of circulating immune complexes is associated with a more severe clinical picture. The development of circulating immune complexes may be a compensatory host response which limits the extent of autoimmune retinal damage. ${ }^{66} \mathrm{~A}$ longitudinal study of 52 patients ${ }^{67}$ showed 79 per cent of patients with relapses demonstrated antiretinal antibodies in the absence of raised circulating immune complexes. These findings further support the hypothesis that circulating immune complexes play a protective role in retinal vasculitis, and that antiretinal autoimmunity is of pathogenic significance. In this study some patients with Behçet's disease were found to have raised circulating immune complexes just before or just after the relapse, though retinal autoantibody levels did not change. There was no change in retinal autoantibody levels in any 

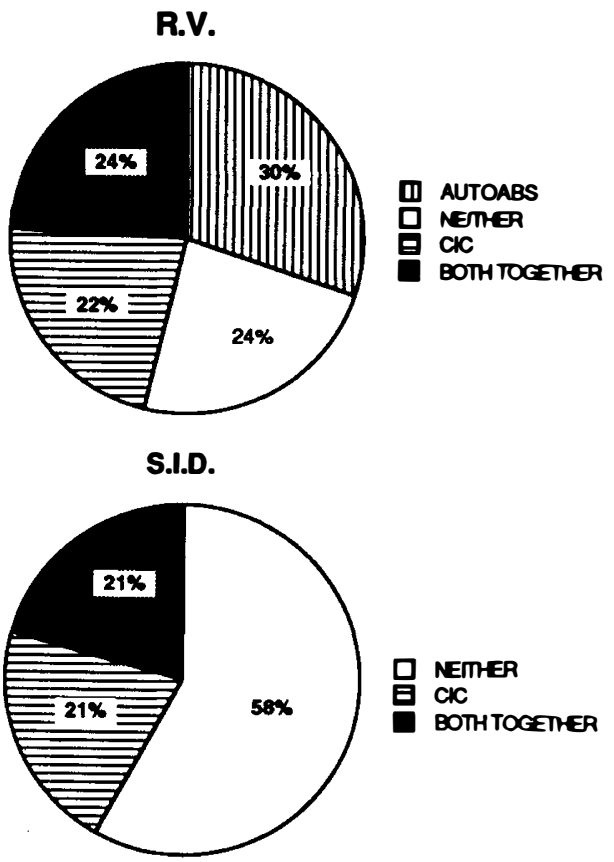

R.V. \& S.I.D.

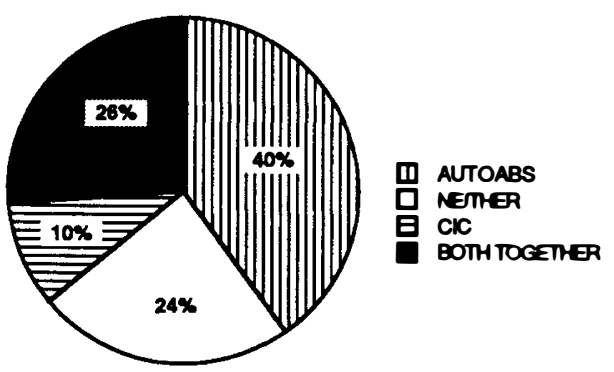

Fig. 8. Retinal Autoimmunity and Circulating Immune Complexes

Three groups of patients were studied: (1) RV (alone) top, (2) Systemic inflammatory disease without $R V$ (middle), and (3) $R V$ and Systemic Inflammatory Disease.

Notable features are that retinal autoantibodies do not occur in systemic inflammatory disease alone unless accompanied by circulating Immune complexes. Secondly, retinal autoantibodies were more commonly seen with SID (40 per cent) than in $R V$ alone (30 per cent).

patients with retinal vasculitis in relation to a relapse.

\section{Experimental Autoimmune Retinal Vasculitis} Elschnig ${ }^{68}$ first considered the notion of an autoimmune reaction as a pathogenic mechanism in ocular disease to explain the aetiology of sympathetic ophthalmia. Organ specific retinal antigens had been described by Hess in 1906 but experimental models were first initiated by Wacker. ${ }^{69} \mathrm{He}$ produced experimental allergic uveitis (EAU) in the guinea-pig after the innoculation of retinal and uveal tissue in Freunds complete adjuvant (FCA). EAU has been produced by the injection of whole retinas, retinal extracts, rod outer segments, and may now be elicited by a single dose of highly purified retinal material (Retinal ' $S$ ' antigen).

The disease in animals is dependent on several factors:

(a) the dose of antigen

(b) The route of administration

(c) The type of adjuvant

(d) The genetic susceptibility of the animal

Retinal ' $S$ ' antigen has been isolated as one of the main retinal antigens and is a $48 \mathrm{~K}$ soluble protein with a high concentration in the rod outer segments. Functionally it may inhibit the activity of the light dependent $3^{\prime} 5^{\prime}$ monophosphate (cyclic GMP) phosphodiesterase. Biochemical characterisation of retinal ' $S$ ' antigen ${ }^{70}$ has led to high levels of purification approaching 80 per cent. Other antigens, such as rhodopsin ${ }^{71}$ and interphotoreceptor binding protein also produce disease, though there are variations in the pattern of disease due to different antigens. ${ }^{72}$

The severity of disease (EAU) produced in the albino rat with marked anterior chamber involvement has precluded fundus examination. Histological examination shows severe destruction of the retina with total photoreceptor loss. A major contribution of our group has therefore been to develop an animal model in which a mild disease producing mainly posterior involvement has enabled us to study the clinical and histological features. ${ }^{67}$ The animal disease closely simulates the disease in man.

The black-hooded Lister rat is economical, available, and the presence of a pigment layer enables fundus photography and fluorescein angiography to be undertaken. After sensitisation with retinal ' $S$ ' antigen in Freunds Complete Adjuvant (FCA), the animals develop disc oedema (Fig. 9a, b) and periphlebitis (Fig. 9c, d). This is followed by deep focal retinal infiltrates. Leakage of dye from the disc and peripheral vessels is seen on 


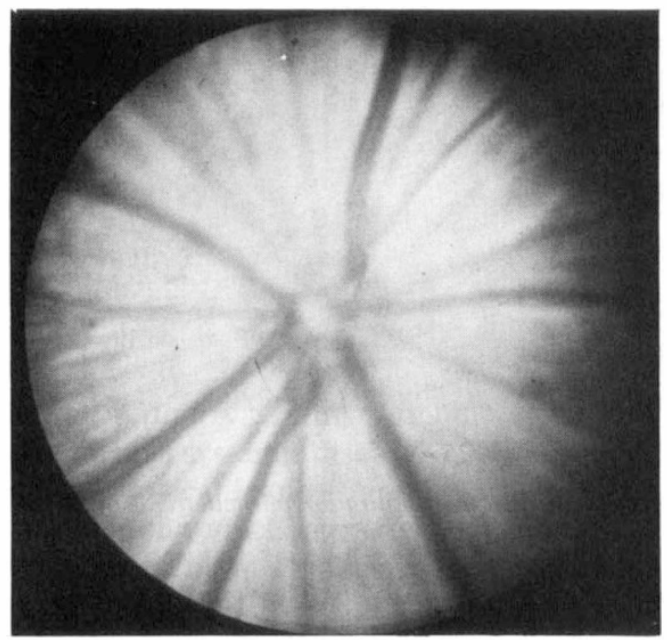

(a)

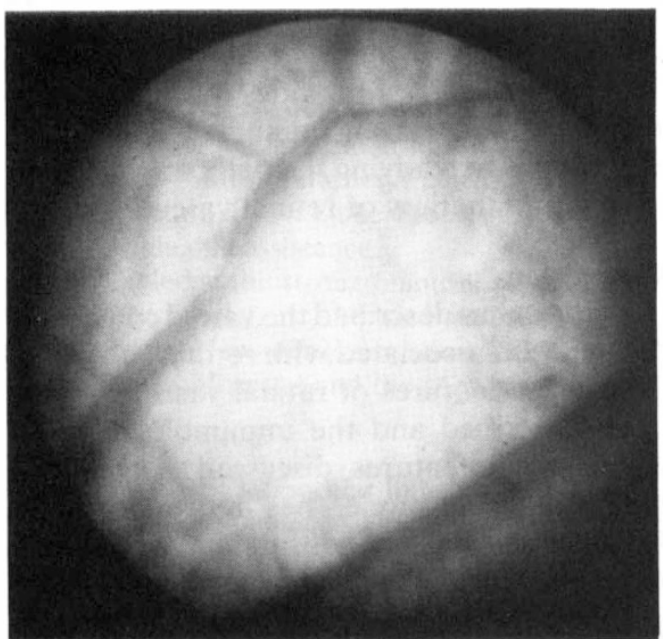

(c)

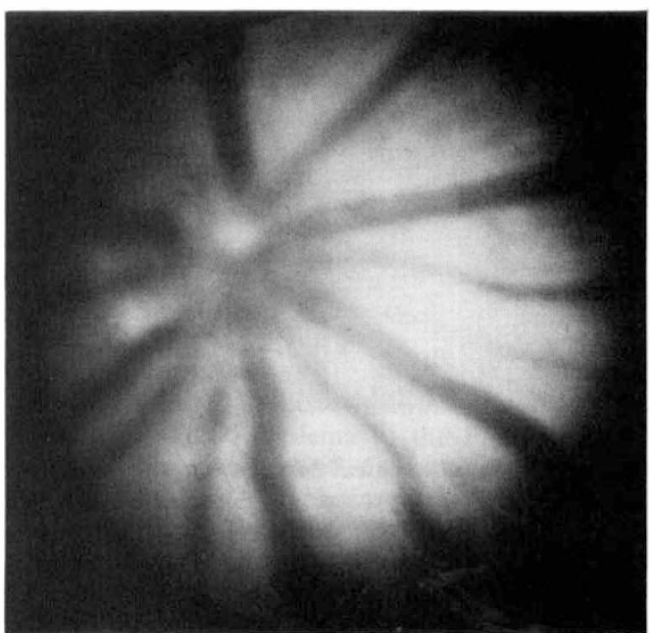

(b)

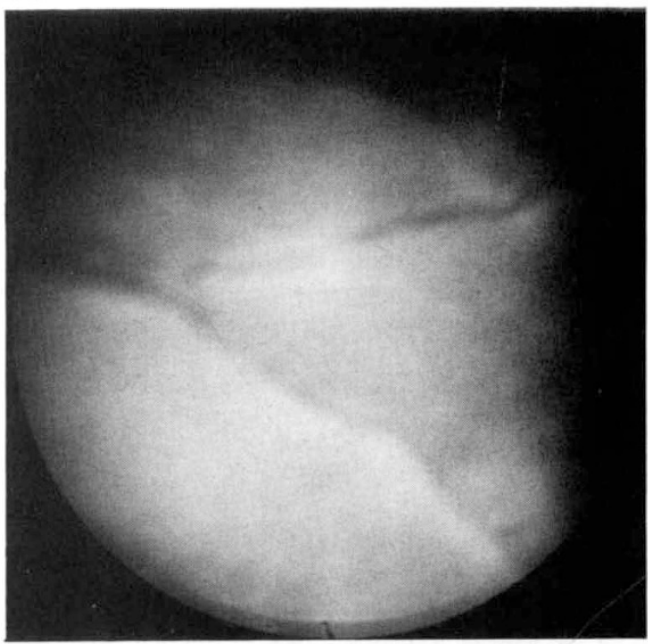

(d)

Fig. 9. Experimental Retinal Vasculitis (ERV)

(a) Normal disc and posterior pole of black-hooded Lister rat (top left).

(b) Swollen disc with dilated retinal vessels 3 weeks after the innoculation of purified retinal ' $S$ ' antigen (top right).

(c) Normal peripheral retina (bottom left).

(d) Focal retinal periphlebitis photographed three weeks after the injection of antigen (bottom right).

fluorescein angiography. Histologically a retinal vasculitis was associated with focal mononuclear cell infiltration of the photoreceptor layers associated with photoreceptor necrosis (Plates 4a, b). The disease only occurred in 90 per cent of the animals sensitised and showed a self limiting course.

Antiretinal antibodies were detected ${ }^{67}$ but there was no correlation between disease activity and antibody levels, an analogous situation to that in man. Adoptive transfer of disease was not attempted although this has been accomplished. ${ }^{73}$

The main feature, however, was the finding that 'retinal vasculitis' may occur without, and before, photoreceptor degeneration (Plate 5). Additionally, choroidal invollvement was minimal so that this again supports the concept of primary retinal involvement. These findings closely simulate the human diseases I have described. We have not produced a retinal arteritis and the animal model has similarities 


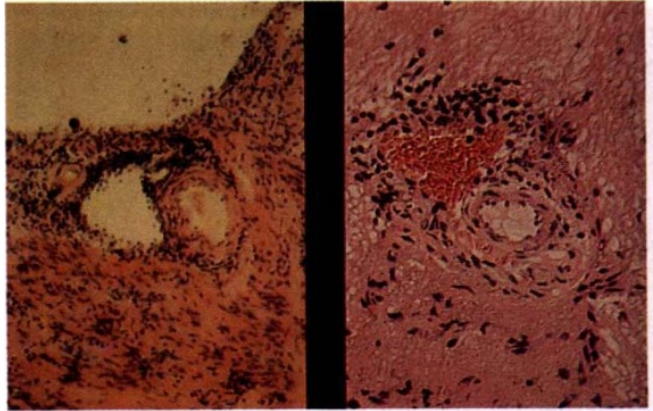

(a)

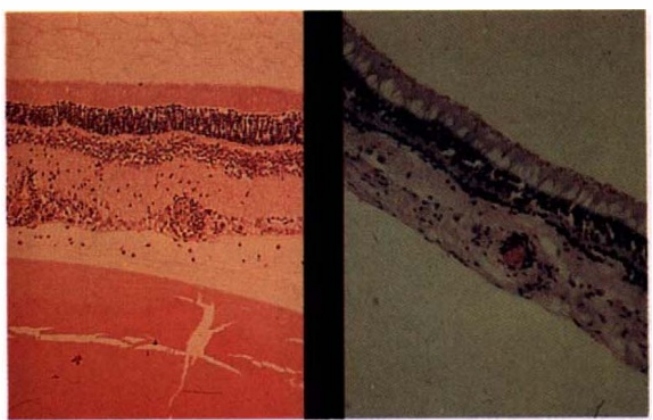

(b)

Plate IV. Histopathological correlation

(a) Optic disc from a patient with Behçet's disease shows marked perivascular infiltration particularly around the veins. The optic nerve is infiltrated and cells are seen entering the vitreous (left). The animal model shows similar changes after innoculation with purified retinal antigen.

(b) Retinal Vasulitis from a patient with Behçet's disease which shows periphlebitis without photoreceptor degeneration (left). The animal model is similar and shows cells infiltrating the vitreous (right).

to Behçet's disease and sarcoidosis, but differs from autoimmune retinal vasculitis (ARV).

The heterogeneity of retinal antigens, and

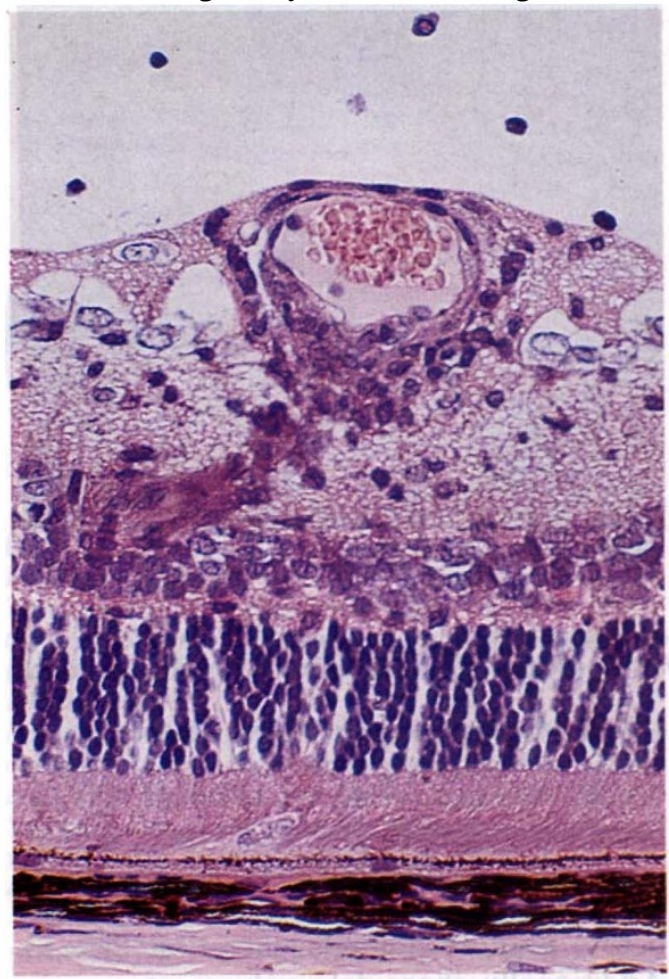

Plate V. Experimental retinal vasculitis

Marked perivascular inflammation of retinal vessel, with cells passing into the vitreous but without photoreceptor degeneration. In addition there is no choroidal involvement demonstrating that the major inflammatory changes are perivascular (from Black-hooded Lister rat after Retinal $S$ antigen). the genetic variability of the recipient, may contribute to the different patterns of disease. The present animal provides a firm platform on which to erect an immunological model with a view to studying the pathology, clinical course and therapy of retinal vasculitis.

\section{Conclusion}

This paper has described the varied conditions that may be associated with retinal vasculitis. Diagnostic features of retinal vasculitis have been described and the immunological and pathological features discussed An experimental animal model has reproduced the human disease and as a result I have been able to come to the following conclusions:

(1) Retinal Vasculitis is a distinct nosological entity which produces severe visual loss due to primary retinal involvement. An animal model confirms the presence of retinal vasculitis without photoreceptor involvement. Use of the term uveitis should therefore be evaluated.

(2) Retinal Arteritis is a specific entity characterised by retinal arterial occlusions without signs of inflammation. Immunopathogenic mechanisms may involve immune complex deposition, the development of antibodies to endothelial cells or their constituents or to neuronal cells. The condition may be idiopathic or associated with proven autoimmune diseases, e.g. systemic lupus erythematosus, Goodpastures Syndrome, Loefflers Syndrome, etc. 
(3) Retinal Vasculitis usually involves the veins and capillaries. This may represent a true inflammatory response against vessel wall constituents or be a secondary response to a primary inflammatory response against retinal constituents such as photoreceptors. The most severe form is seen in Behçet's disease, though sarcoidosis, HLA-B27 disease may also be responsible.

(4) Autoimmune Retinal Vasculitis is an idiopathic retinal vasculitis without any association with a systemic disease. The clinical and immunological features are described and an autoimmune mechanism is postulated. This may represent an organ specific autoimmune disease.

I would like to thank Dr. E. M. Graham, Mr. M. R. Stanford, Professor D. C. Dumonde and Dr. G. James for their support and advice in this work. Photographic assistance was provided by Mr. R. Dewhirst and secretarial assistance by Miss $\mathbf{M}$. May, to both of whom I am grateful. I would also like to thank Profesor Garner, Professor Denman, Dr. Davies and Lady Duke-Elder, all of whom provided valuable assistance.

I acknowledge the strong financial support provided by the Frost Trust, the Iris Fund, the Frances and Augustus Newman Foundation, the Trustees of St Thomas' Hospital and the Medical Research Council.

\section{References}

${ }^{1}$ Nussenblatt RB: Intraocular Inflammatory Disease (Uveitis) Autoimmune Disease. Triangle 1984, 23: $125-32$.

${ }^{2}$ Observations of the Inflammation of the Internal Coats of Veins. Transactions of a Society for the Improvement of Medical and Surgical Knowledge 1793, 1: 18 .

${ }^{3}$ Parsons JH: The Pathology of the Eye. 1905, Vol 11, Histology Part II. 567-82. Hodder and Stoughton, London.

${ }^{4}$ Eales H: Primary Retinal Haemorrhage in Young Men. Ophthal rev 1882, 1: 41.

${ }^{5}$ Axenfeld T and Stock W: Uber die Bedentung der Tuberkulose in der Aetiologie der Intra-ocularen Haemorrhagen und die Proliferienden Veranderungen in die Netzhaut. Klin Mbl Augenheilk 1911, 49: 28

${ }^{6}$ Duke-Elder S: Systems of Ophthalmology. Volume X, p. 221, Henry Kimpton, London.

${ }^{7}$ Ballantyne $\mathrm{A} \mathrm{J}$ and Michaelson IC: Textbook of the Fundus of the Eye. 1970, 269-76. E. \& S. Livingstone, Edinburgh and London.

${ }^{8}$ Sanders MD: Retinal Vasculitis, A Review. J Roy Soc Med 1979, 72: 908-15.

${ }^{9}$ Lyle TK and Wybar KC: Retinal Vasculitis. Br J Ophthalmol 1961, 45: 778.

${ }^{10}$ Hart CD, Sanders MD, Miller SJH: Benign Retinal
Vasculitis. Clinical and Fluorescein Angiographic Study. Br J Ophthalmol 1971, 55: 721-33.

${ }^{11}$ MacKenzie W: A Practical Treatise on the Diseases of the Eye. 1840. Longman, Orme, Brown, Green and Longmans.

${ }^{12}$ Leibreich R: Atlas of Ophthalmolscopy. 1870. John Churchill and Company, London.

${ }^{13}$ Schepens CL: L'inflammation de la region de l'ora serrata et ses sequelles. Bull Mim Soc Fr Ophtalmol 1950, 73: 113-24.

${ }^{14}$ Welsh RB, Maumenee AE, Whelan HE: Peripheral Posterior Segment Inflammation, Vitreous Opacities and Oedema of the Posterior Pole. Arch Ophthalmol 1960, 64: 540-9.

${ }^{15}$ Maumenee AE: Introduction to Ocular Inflammatory Disease. In: Selected Topics on the Eye in Systemic Disease. Ed. Ryan SJ and Smith RE: Grune and Stratton, New York, 1974, 121-2.

${ }^{16}$ Fan PT, Davis JA, Somer T, et al.: A Clinical Approach to Systemic Vasculitis. Seminar Arthritis and Rheum 1980, 9: 248-304.

${ }^{17}$ Cochrane CG and Dixin FJ: Antigen Antibody Complex Induced Disease. In: Textbook of Immunopathology. Ed. Meischer PA, MullerEberhard HJ. Grune and Stratton, New York. 1976, 2nd Ed. Vol. 1. p. 137.

${ }^{18}$ Kussmaul A und Maier R: Ueber eine bishir nicht beshriebene iegenthumliche arterienkrunkung (periarteritis nodosaa) die mit Merbus Borghtii und rapid fortschreitender allgemeiner Musbellahmung einhergeht. Deutch Arch Klin Med 1866, 1: 484-517.

${ }^{19}$ Gillian JN and Smiley JD: Cutaneous necrotising vasculitis and related diseases. Ann Allergy 1976, 37: 328-39.

${ }^{20}$ Ryan TJ: Vasculitis; Immunology and Localisation. J Roy Soc Med 1979, 72: 527-9.

${ }^{21}$ Churg J and Strauss L: Allergic granulomatosis, allergic angiitis and periarteritis nodosa. Am J Pathol 1951, 27: 227-302.

${ }^{22}$ Elliott A: Recurrent Intraocular Haemorrhagia in Young Adults. Trans Am Ophthalmol Soc 1954, 52: 811 .

${ }^{23}$ Verhoeff FH and Simpson GV: Tubercule within the Central Retinal Vein. Arch Ophthalmol 1940, 24: 645-52.

${ }^{24}$ Shah SH, Howard RS, Sarkies NJC, Graham EM: Tuberculosis presenting as retinal vasculitis. Proc Roy Soc Med 1987 (In Press).

${ }^{25}$ Urayama A, Yamada N, Sasaki T, Nishiyana Y, Watanabe H, Wakusawa Y, Takahashi K, Takei Y: Unilateral acute uveitis with retinal periarteritis and detachment. Jap J Clin Ophthalmol 1971, 25: 607 .

26 Young NJ and Bird AC: Bilateral Acute Retinal Necrosis. Br J Ophthalmol 1978, 62: 581.

${ }^{27}$ Saari KM: Association of Acute Retinal Necrosis with Herpetic Infection. Uveitis Update. Elsevier Science Publ. Ed. KM Saari. Excerpta Medical International Congress Series. Excerpta Medica Amsterdam, New York, Oxford. 1984. p. 233. 
${ }^{28}$ Arruga JA, Valentines J, Mauri F, Roca G, Salon R, Rufi G: Neuroretinitis in Acquired Syphilis. Ophthalmology 1985, 92: 262-70.

${ }^{29}$ Newsome DA: Retinal Fluorescein Leakage in Retinitis Pigmentosa. Am J Ophthalmol 1986, 101: 354-60.

${ }^{30}$ Spalton DJ, Graham EM, Page NGR, Sanders MD: Ocular changes in limited forms of Wegeners granulomatosis. $\mathrm{Br} J$ Ophthalmol 1981, 65: 553-63.

31 Ayesh I, Sanders MD, Friedmann AI: Retinitis pigmentosa and Coats' Disease. Br J Ophthalmol 1976, 60: 775-7.

${ }^{32}$ Heckenlively JR, Solish AM, Chant SM, Meyer Elliott RH: Autoimmunity in hereditary retinal degenerations II. Clinical Studies: Antiretinal antibodies and fluorescein angiogram findings. Br J Ophthalmol 1985, 69: 758-64.

33 Janzer RC and Raff MC: Astrocytes induced blood brain barrier properties in endothelial cells. Nature 1987, 325: 253-7.

${ }^{34}$ Sawyer RA, Selhorst JB, Zimmerman LE, Hoyt WF: Blindness caused by a photoreceptor degeneration as a remote effect of cancer. Am J Ophthalmol 1976, 81: 606-13.

${ }^{35}$ Klingele TG, Burde RM, Rappazzo JA, Isserman MJ, Burgess D, Kantor O: Paranerplastic Retinopathy. J Clin Neuro-ophthalmol 1984, 4: 239-45.

${ }^{36}$ Keltner JL, Roth AM, Chang S: Photoreceptor Degeneration. A possible autoimmune disease. Arch Ophthalmol 1983, 101: 564-9.

${ }^{37}$ Knox DL: Ischaemic occular inflammation. Am J Ophthalmol 1965, 60: 995.

38 Wise GN, Dollery CT, Henkind P: The Retinal Circulation. Harper and Row, New York. 1971.

${ }^{39}$ Rothova A, Kiljstra A, Buitenhuis HJ, van der Gag R, Feltkamp EW: HLA B27 Associated Uveitis-A Distinct Clinical Entity. Elsevier Science Publ. Uveitis Update. Ed. Saari KM. Excerpta Medical International Congress Series. Excerpta Medica Amsterdam, New York, Oxford. 1984.

${ }^{40}$ Rucker CW: Sheathing of the Retinal Veins in Multiple Sclerosis. Proc Staff Mtg Mayo Clinic 1944, 19: $176-8$.

${ }^{41}$ Arnbold AC, Pepose JS, Hepler RS, Foos RY: Retinal Periphlebitis and Reinitis in Multiple Sclerosis. Ophthalmology 1984, 91: 255-61.

42 Jampol LM, Lahar M, Albert DM: Ocular clinical findings and basement membrane changes in Goodpastures Syndrome. Am J Ophthalmol 1975, 79: 452-63.

${ }^{43}$ Orzalesi N and Ricciardi L: Segmental retinal periarteritis. Am J Ophthalmol 1971, 72: 55-9.

${ }^{44}$ Gass JDM, Tiedeman J, Thomas MA: Idiopathic Recurrent Branch Retinal Artery Occlusion. Ophthalmology 1986, 93: 1148-57.

${ }^{45}$ Susac JO, Hardman JM, Sellhorst JB: Microangiopathy of the Brain and Retina. Neurology 1979, 29: 313-6.
${ }^{46}$ Delaney WV and Torrisi PF: Occlusive Retinal Disease and Deafness. Am J Ophthalmol 1976, 82: $232-6$.

${ }^{47}$ Zeek PM: Periarteritis Nodosa, A Critical Review. Am J Clin Pathol 1952, 22: 777-90.

48 Wegener F: Uber generaliseite, septische getasserkarnkungen. Verl Dtsch Ges Pathol 1936, 29: $202-10$.

${ }^{49}$ Haynes BF, Fishman ML, Fauci AS, Wolf SM: The Ocular Manifestations of Wegeners granulomatosis. Am J Med 1977. 63: 131-41.

${ }^{50}$ Hughes GRV: Thrombosis, abortion, cerebral disease and the lupus anticoagulant. $\mathrm{Br}$ Med $\mathrm{J}$ 1983, 287: 1088-9.

${ }^{51}$ Graham EM, Spalton DJ, Barnard RO, Garner A, Ross-Russel R W: Cerebral and Retinal Changes in Systemic Lupus Erythematosus. Ophthalmology 1985, 92: 444-8.

52 Goodpastures EW: The significance of certain pulmonary lesions in relation to the aetiology of influenza. Am J Med Sci 1919, 158: 863.

${ }^{53}$ Dagi LR and Currie J: Branch retinal artery occlusion in the Churg-Strauss Syndrome. J Clin Neuro-ophthalmol 1985, 5: 229-37.

${ }^{54}$ Weinstein JM, Chui H, Lane S: Churg Strauss Syndrome (Allergic granulomatous angiitis). Arch Ophthalmol 1983, 101: 1217-20.

${ }^{55}$ Chusid MJ, Dale DC, West BC, Wolff SM: The Hypereosinophilic Syndrome. Medicine 1977, 54: 1-27.

${ }^{56}$ Nussenblatt RB, Gery IG, Ballintine EJ, Wacker WB: Cellular Immune Responsiveness of Uveitis Patients to Retinal S Antigen. Am J Ophthalmol 1980, 89: 173-9.

${ }^{57}$ Siltzbach LE, James DG, Neville E, Turia FJ, Battesh JP, Sharma OMP, Hosada Y, Mikami R, Odaka M: Course and prognosis of sarcoidosis around the world. Am J Med 1985, 57: 847.

58 Jabs DA and Johns CJ: Ocular involvement in chronic sarcoidosis. Am J Ophthalmol 1986, 102: 297.

${ }^{59}$ Sanders MD and Shilling JS: Retinal choroidal and optic disc involvement in sarcoidosis. Trans Ophthalmol Soc UK 1976, XCVI: 140-4.

${ }^{60}$ Michelson JB and Chisari FV: Behçet's disease. Surv Ophthalmol 1982, 26: 190-203.

${ }^{61}$ Lehner $\mathrm{T}$ and Batchelor JR: Classification and Immunogenetic Basis of Behçet's Syndrome. In: Behçet's Syndrome. Ed. Lehner T and Barnes CG. Academic Press, London. 1979.

62 Sanders MD: Ophthalmic features of Behçet's Disease. In: Behçet's Syndrome. Ed. Lehner T and Barnes CG. Academic Press, London. 1979. pp. 183-9.

${ }^{63}$ Mamo JG: The rate of visual loss in Behçet's disease. Arch Ophthalmol 1970, 84: 451-2.

${ }^{64}$ Shimizu T and Saito Y: Behçet's Syndrome. Clin Sci 1971, 17: 451-3.

${ }^{65}$ Dumonde DC, Kasp Grochowska E, Graham EM, Sanders MD, Faure JP, Kozak Y, Tuyen V: Antiretinal autoimmunity and circulating immune complexes in patients with retinal vasculitis. $L$ ancet 1982, ii: 787-92. 
${ }^{66}$ Kasp-Grochowska E, Graham E, Sanders MD, Dumonde DC, Kozak Y, Tuyen V, Faure JP: Autoimmunity and circulating immune complexes in retinal vasculitis. Trans Ophthalmol Soc UK 1981, CI: 342-8.

${ }^{67}$ Stanford MR, Brown EC, Kasp E, Graham E, Sanders MD, Dumonde DC: Experimental Posterior Uveitis I. A clinical angiographic and pathological study. Br J Ophthalmol 1987 (In Press).

${ }^{68}$ Elschnig A: Studien zur sympathischen ophthalmis. Die Antigene Wirkung des Angenpigmentes. Albrecht von Graefes Arch Ophthalmol 1910, 76: 509-46.

${ }^{69}$ Wacker WB and Lipton MM: Experimental Allergic Uveitis I. Production in the guinea pig and rabbit by immunization with retina in adjuvant. $J$ Immunol 1968, 101: 151-6.

${ }^{70}$ Banga JP, Kasp E, Brown EC, Suleyman S, Ellis B,
Sanders MD, Dumonde DC: Comparative biochemical analysis of purified retinal $\mathrm{S}$ antigen from human, bovine, porcine and rat retina. Exp Eye Res (In Press).

${ }^{71}$ Marak GE, Shichi H, Rao NA, Wacker WB: Patterns of experimental allergic uveitis induced by rhodopsin and retinal rod outer segments. Ophthalmic Res 1980, 12: 165-76.

72 Brockhuyse RM, Winkers HJ, Kuhlman ED: Induction of experimental autoimmune uveoretinitis and pinealitis by IRBP. Comparison to uveoretinitis induced by S-antigen and opsin. Curr Eye Res 1986, 5: 231-40.

${ }^{73}$ Mochizuki M, Kuwabara T, McAllister C: Adoptive transfer of experimental autoimmune uveoretinitis in rats: Immunopathogenic mechanisms and histological features. Invest Ophthalmol Vis Sci 1985, 26: 1-9. 